\title{
FACTORS AFFECTING GERMINATION AND EARLY SURVIVAL OF YELLOW BIRCH (Betula lutea Michx.) IN QUEBEC ${ }^{1}$
}

\author{
BY ANDRÉ LINTEAU
}

Department of Lands and Forests, 2uebec, P.2. REVIEW OF LITERATURE

Very few studies directly concerning the factors which favor yellow birch reproduction can be found in the bulk of literature on the management of Northern Hardwoods. A number of papers exist, however, which show the place of yellow birch in virgin and cut-over forest stands. The only intensive investigation ever made of the species was conducted in the Adirondack Forest by McCarthy and Belyea (1920). The writers mentioned among others the following facts leading to the study of the species: yellow birch possesses certain advantages over the three important competing hardwoods - beech, sugar maple, and red maple--in seizure of devastated areas. These advantages are the greater motility of yellow birch seeds; large annual crops of seeds having few enemies; the capacity of the seeds to germinate on deep humus or partially decayed wood and successful rooting through deep layers of such material to the mineral soil; the species in its seedling and sapling stages grows quickly enough to compete with tolerant hardwoods and assures the tree a dominant place in the ultimate stand of trees. Moreover, the crown of birch intercepts less light than those of the maples and beech, so that it allows a better growth of the understory of softwoods. Finally, cut-over lands were observed to have dense stands of young birch, and it was believed that the ultimate forest would have a larger percentage of birch than the virgin forest.

A survey of cut-over lands made by McCarthy and Belyea showed that cutting to a 10-inch diameter limit in the hardwood type resulted in poor reproduction of yellow birch and in a considerably greater representation of the maples and beech. This light cutting was not enough to open up the crown canopy. Cutting all merchantable timber in the same type had the contrary effect on species representation. Lower slopes where seepage was an important factor resulted in more yellow birch than maple reproduction, while on the upper and drier zone the latter species predominated after cutting. Piling of brush on areas subjected to heavy cutting in a softwood type resulted in the invasion of raspberry briars. Softwood reproduction was poor due to the drying of the surface humus layer, and red maple formed the greater part of the reproduction. A fire which swept through a cut-over area in the hardwood type resulted, five years later, in the presence of a large number of intolerant species such as cherry and aspen. Red maple and sugar maple accounted for 16 per cent and yellow birch for 9 per cent of the entire reproduction stand. Eventual establishment of pure yellow birch stands after fire was observed in the sections studied but apparently they never covered large areas.

IA dissertation presented to the Faculty of the Graduate School of Yale University in candidacy for the degree of Doctor of Philosophy, 1946. 
In a study of hardwood reproduction on cut-over lands in the Northeast, Jensen (1943) stated that all types of treatments usually favor an abundant reproduction but this new growth is not always of the desired composition. After a clear-cutting operation in a 15 -acre hardwood stand, natural regeneration was shown to be dominated by intolerant species. The maples accounted for a third of the stand in the new forest whereas yellow birch constituted less than one-eleventh.

A comprehensive survey of cut-over lands in the Lake States was recently completed by Zillgitt and Eyre (1945) with a view to finding the best treatments which might assure the perpetuation of yellow birch. The main results of their investigation were formulated in this manner: following commercial clear-cutting of Northern Hardwoods, yellow birch maintains itself in the second-growth forest in about the same proportion as in the original stand. Light selection cuttings where a uniform canopy is maintained are unsuited to yellow birch regeneration. Since the species cannot compete under shade with the more tolerant species, especially sugar maple, moder. ate selection cutting with openings resulting from the removal of small groups of poor-risk trees are also successful in this respect. In the application of the group-selection system suggested, the following are believed to be essential requirements to obtain an adequate yellow birch reproduction: (1) assurance of an ample seed supply by leaving seed trees within a reason. able distance of the area to be seeded, not over 300 to 400 feet in heavy stands, and preferably much closer; (2) exposure of the mineral soil through summer or fall logging; and (3) provision for sufficient light by creating small openings, up to 0.1 acre in size, scattered through the tract.

\section{GENERAL HABITAT AND FOREST TYPES}

\section{Forest Types and Successional Relations}

A survey of forest conditions in the main forest regions of Quebec seems to indicate that yellow birch thrives best on a rather well-defined range of sites.

In the Northern Conifers region yellow birch is generally excluded, not so much on account of the poverty of soils as because of the limiting effect of the climate. The species, however, is occasionally found in certain valleys where protection is afforded against the winds and colder temperatures which prevail at higher altitudes.

Immediately south of the Northern Conifers region proper is a tension zone of mixed forests where hardwoods and softwoods alternately dominate or intermingle according to the influence of soil conditions. In this region, yellow birch has a high representation.

Along that part of Quebec bordering on Vermont, New Hampshire and New York is a belt of forests which definitely belong to the Northern Hardwood formation. Here the soils are of the same quality as those of the tension zone. Yellow birch is present on all but the driest and wettest sites. The latter are occupied by softwood forests exclusively, which represent physiographic climax communities. 
In the regions where the climate is favorable, yellow birch seems to require soils having a good water-holding capacity. Moreover, a colloidal fraction of 10 per cent appears to be a minimum. At the lower limit of productivity are the wet softwood sites, such as cedar swamps. At the upper level are rich loamy soils, located mostly in the southwestern part of the province, where thrive the most mesophytic hardwood forests. The representation of yellow birch on these sites is generally restricted to scattered individuals. In the first case, shallowness of the soil or a thick accumulation of raw humus favors cedar, fir, spruce, and larch. The associate species, not all of which are present in a given stand, are white birch, black ash, red maple, yellow birch, and, less frequently, hemlock and hop hornbeam. On the most fertile soils hardwood competition among the broadleaved species is no doubt the factor which limits the abundance of yellow birch. On such sites are found the better forms of mor humus layers, and mull types are not infrequent. The most common combination of species here is the follow. ing: sugar maple, white ash, basswood, yellow birch, red maple, white elm, balsam fir, white spruce, eastern hemlock, white pine, white birch, hop hornbeam, and beech. One of the usual associations is comprised of hard maple, yellow birch, white ash, basswood and beech, with or without slight admixture of spruce, fir, and hemlock. Cedar and elm are sometimes present in very moist situations. The latter conditions are mostly found on flats or plains.

Between the extreme sites mentioned is a whole series of fresh soils, usually sandy loams, which give rise to various types of stands. These are mixed or pure hardwoods and for the most part represent upland types. The poorest types reveal an abundance of spruce and fir with few hardwoods, usually yellow birch, white birch, and red or hard maple. More fertile soils support hardwood-softwood stands where yellow birch and hard maple predominate, followed by spruce and fir. The hardwood type is commonly composed of hard maple, yellow birch and beech, with a small amount of spruce and fir. Other species, such as red maple, white birch, hemlock, white pine, basswood and cedar, are sometimes present but their appearance is local in character, some of them being representative of the southwestern part of the hardwood region, others of the eastern extension.

The aforementioned forest stands of the upland areas constitute climatic climax types; those growing on wet locations, being more the product of the soil or drainage conditions, form physiographic climax forests.

The types briefly described above belong to the region which Nichols called the Hemlock-White Pine-Northern Hardwoods region (Nichols, 1935). He correctly observed that, "In its larger and more general aspects, the nature of the climatic climax forest is very much the same throughout. In its detailed local structure, however, and especially in the identity and relative abundance of the different tree and shrub species it exhibits a considerable degree of variation, both in different parts of the region and locally in the same part." 
Successful trends after fire or cuttings have in general not been studied and are consequently imperfectly known. Upon destruction softwood as well as hardwood types are replaced by short-lived, intolerant species such as gray and white birch and trembling aspen. Jack pine, which is a subclimax species, appears most frequently in pine stands on softwood sites. Black cherry is found with the other species on hardwood sites. Quite frequently on softwood sites an undergrowth of spruce and fir establishes itself as soon as the canopy of the intolerant, pioneer species closes.

Under especially favorable conditions, when a source of seed is at hand, yellow birch will take the lead after a fire on fresh soils. Such conditions are a heavy seed crop and an exposed mineral soil. The species will then act as white birch or aspen but its longevity will insure it a place in the climax forest. This role of pioneer is more frequently played by the maples in spite of their shade-tolerant character. If yellow birch comes in at the same time it is likely to be outnumbered by the maples.

As for the effect of cuttings on species representation, certain types of operation seem to bring no regression in the climax species; others introduce new elements of competition. If by experimentation or systematic observation the extent of changes brought about in the environmental factors are known, one is in a position to ascertain which treatments may be recommended so that a type or a species may be perpetuated or increased.

\section{Climatic and Soll Condrtions}

The locality where the present study was initiated lies some thirty miles northwest of Quebec city. It is included in the eastern part of the HemlockWhite Pine-Northern Hardwoods region as described by Nichols (1935), and more precisely in the Algonquin-Laurentides section of the Great LakesSt. Lawrence forest region of Halliday (1937). The association of maple, yellow birch and, to a lesser extent, beech forms the characteristic upland type.

In a general way, the climate is related to the humid microthermal province of Thornthwaite (1931). Halliday (1937), defining the climatic features for each section of the forest regions of Canada on the basis of Thornthwaite's work, termed the Algonquin-Laurentides section a humid (+) temperate province ( $\left.\mathrm{B} \cdot \mathrm{rC} \mathrm{C}^{\prime} \mathrm{c}\right)$ with moisture abundant at all seasons and $\mathrm{a}$ 50.69 per cent summer concentration of temperature. With regard to Duchesnay where the study was made, the annual precipitation amounts to about 49 inches and is well distributed over the year with a peak during the summer months. In fact, from June to September it normally totals 5 inches and more every month, while throughout the other seasons it fluctuates between 3 and 4 inches. The mean maximum temperature of the summer months is $70.7^{\circ} \mathrm{F}$. and the average for the same period is $60.1^{\circ} \mathrm{F}$.

Duchesnay lies at the margin of the Laurentides Mountains and the paleozoic lowland extending a few miles north of the St. Lawrence River. The elevation is about 600 feet. The parent material of the soil is largely unmodified glacial till derived from gneiss and granite. With respect to 
the great groups, the soils concerned would be classified as podzols or brown podzolic soils. The mineral soil is usually a sandy loam, and the total depth of the solum varies between 30 to 60 inches. The humus layer type is generally a granular mor, and less frequently a fine mull.

Description of The Experumental Area

To make valid the results of the investigation carried out during the summers of 1944 and 1945 , certain preliminary conditions had to be fulfilled. Three areas were selected which differed only in the density of canopy. Soil, topography and vegetation had to be uniform throughout, so that relative growth and survival of seedlings artificially established would not be contingent on variations of fertility, aspect or drainage.

Before deciding on the proper location, a careful examination of the terrain was made. The choice finally rested on a lower southwestern slope provided with apparently similar drainage conditions throughout and covered with the same type of forest. The latter consisted of a 70-year old hardwood type with the following stem distribution percentage: yellow birch, 60.6; hard maple, 16.7; red maple, 13.9; balsam fir, 5.7; beech, 2.3; black cherry, 0.5; red spruce, 0.2; and large-tooth aspen, 0.1. For further details the reader is referred to the stand table in the Appendix. A part of the area had not been disturbed recently by any cutting operation and provided the full canopy under which a one-acre plot or station was established. In the immediate vicinity another one-acre plot was located where a few years previously a cutting operation had removed nearly 40 per cent of the stand volume. The clear-cut station was made available when in the fall of 1943 the students of the Ranger School at Duchesnay logged a 3-acre stand in the area selected.

The lesser vegetation within the experimental area was investigated using $1.5 \times 1.5$ foot plots as the sampling unit. Twenty-five such plots were taken at random at each of the one-acre stations. Herbaceous species and tree seedlings were recorded on each plot. The summary sheets (see Appendix) show the presence and coverage of the different species. This means of characterizing vegetation was devised by Nichols (1918) when studying the structure of plant communities in a number of forest types of Cape Breton Island. It was used recently by Egler (1940) in his investigation of the Berkshire Plateau vegetation.

It appears from the Duchesnay data that although the site is favorable for softwoods it is equally, if not more, favorable for hardwoods and in particular yellow birch. Analysis of the lesser vegetation shows a close agreement with the Viburnum-Oxalis site-type as defined by Heimburger (1941) for the Lake Edward area. Heimburger found this type commonly occurring at the Valcartier Forest Experiment Station, which is very close to Duchesnay, and to some extent at the foothills of the Laurentides Mountains near Laval. The forest type corresponds also to a similar one described by Westveld (1931) in the northeastern United States. The poor representation of softwood species in the area selected for this study at Duchesnay is no doubt due to their having been culled from the stands at the turn of the century. 
Soil texture was examined by means of a mechanical analysis. Composite samples were collected at each station from horizons $A$ and $B$. The results are presented in Table 1.

TABLE 1

Mechanical Aanalysis of A and B Horizons of 3 Soils from the Duchesnay Experimental Area

\begin{tabular}{|c|c|c|c|}
\hline $\begin{array}{c}\text { Soil } \\
\text { Fraction }\end{array}$ & $\begin{array}{c}\text { Station I } \\
\text { (Full Canopy) }\end{array}$ & $\begin{array}{c}\text { Station II } \\
\text { (Partial Canopy) }\end{array}$ & $\begin{array}{l}\text { Station III } \\
\text { (Open) }\end{array}$ \\
\hline \multicolumn{4}{|l|}{ Horizon A: } \\
\hline Sand $\ldots$ & 59.94 & 57.94 & 56.46 \\
\hline Silt . & 33.16 & 34.91 & 38.93 \\
\hline Clay ..... & 6.90 & 7.15 & 4.61 \\
\hline Finer Clay ..... & 4.03 & 3.50 & 3.65 \\
\hline "Total Colloids" & 13.52 & 12.29 & 12.77 \\
\hline \multicolumn{4}{|l|}{ Horizon B: } \\
\hline Sand .. & 61.61 & 54.38 & 63.16 \\
\hline Silt. & 32.67 & 39.97 & 30.51 \\
\hline Clay & 5.72 & 5.65 & 6.33 \\
\hline Finer Clay ..... & 4.69 & 3.55 & 5.64 \\
\hline "Total Colloids" & 11.61 & 11.09 & 12.05 \\
\hline
\end{tabular}

There are slight variations in the percentages of the different fractions but they are not believed to be large enough to affect significantly germination and growth of seedlings.

A knowledge of soil moisture availability for plant use is desirable in a study of water relations. The lower limit or wilting coefficient is of great help in diagnosing drought losses. In this connection the indirect method proposed by Briggs and Shantz (1912) and involving determination of the moisture equivalent was resorted to and applied to multiple samples from horizon $\mathrm{A}$ of the three soils concerned. The usual procedure devised by Veihmeyer, Israelsen and Conrad (1924) to determine moisture equivalent was followed. The values obtained were 16.15, 17.04, and 18.79 per cent for Stations I, II, and III, respectively. Utilizing the ratio of 1.84, the moisture equivalent values were converted to wilting coefficients for stations I, II, III; the wilting coefficients were $8.78,9.26$, and 10.21, respectively. It is admitted that this ratio varies with soil types, but for those of a medium texture, such as the Duchesnay soils, the discrepancy is likely to be of little import.

Soil samples collected in the fall of 1943 from the three experimental areas were lifted without disturbing their structure and sown to yellow birch to test the influence of possible differences of soil fertility levels. Grown under similar light, moisture, and temperature condition for a period of four months, the seedlings did not show any appreciable difference in their growth or health conditions. Consequently, it is evident that soil conditions were essentially similar at the three stations utilized in this investigation. 


\section{GERMINATION YELLOW BIRCH - LINTEAU \\ EXPERIMENTAL PROCEDURE \\ DESIGN OF EXPERIMENT}

For purposes of statistical analysis, the plot arrangement of the experiment was originally designed to include three degrees of cover and three soil conditions; namely, mineral soil, litter, and burnt litter. Each surface condition was to be replicated three times with three quadrats in each replication. Unfortunately, one of the surface conditions, burnt litter, could not be provided when the quadrats were laid out in the fall of 1943, due to the incidence of frequent heavy rainfalls. The blocks which were established consisted of two surface conditions.

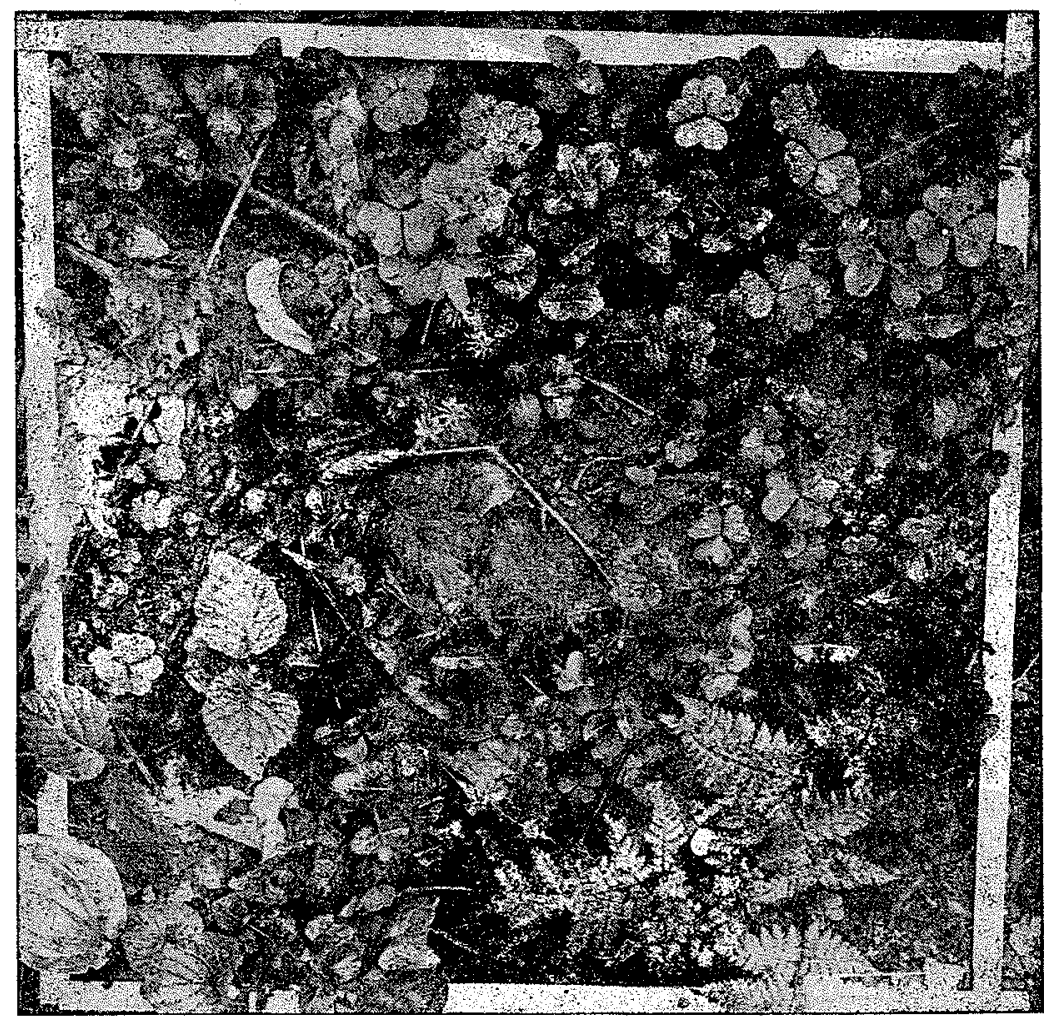

Typical ground vegetation under a yellow birch-maple stand.

The quadrats established under the three canopy conditions consisted of $3 \times 3 \mathrm{ft}$. plots. Sowing on mineral soil involved the removal of the litter and other unincorporated organic matter. Great care was exercised in the location of the groups of quadrats, so that they would receive about the same amount of light under a given canopy condition. Moreover, for practical reasons it was necessary not to scatter them too much. In spite of the effort to provide comparable light conditions, two replications at the 
partial-canopy station were found later to be quite similar in this respect to those of Station I. This fact was recognized and taken into account in the course of the field work as well as in the analysis of the final data. It ap. pears clearly from this experiment that in work of this nature the greatest care should be taken when dealing with hardwood stands because of the irregularity of their crown canopy as compared with that of softwoods. An equal number of unseeded quadrats were under observation during the seasons of 1944 and 1945. These served as control plots. Comparative analyses are reported in a later section.

\section{INSTRUMENTATION}

A number of weather instruments were installed at each station in 1944. These included thermographs, hygrographs, and maximum and minimum air thermometers. Sling psychrometers were used as a check on the hygrographs. A pair of maximum thermometers for surface soil temperature was also available at each station. Rain gauges of the usual type were also installed in pairs. Radiation intensity and evaporation were measured by means of the Livingston porous cup atmometers. Anemometers set up at each station at the beginning of the 1944 season were later removed due to their lack of sensitivity on the timbered plots.

Soil moisture values were obtained in situ in the mineral soil quadrats by means of electrodes imbedded in blocks of plaster of paris and readings were made with a modified Wheatstone bridge as described by Bouyoucos and Mick (1940). Because a close contact of the blocks with the surround.. ing material cannot be obtained in the case of litter or humus, moisture values for this type of surface material were secured by collecting and ovendrying samples.

On account of war conditions, only a minimum number of instruments were obtainable. Instrumentation in 1945 was the same as in 1944.

Routine Measurements and Observations

Before sowing in the fall of 1943 , a lot of seeds obtained from the Berthierville Provincial Nursery was sampled and a germination test was initiated. On the basis of the results, enough seed was sown to obtain under field conditions about fifty seedlings per square foot. An equal amount of seed was used on all the quadrats.

At the beginning of June, 1944, germinated seedlings were marked with wooden pins, and the same procedure was used as new plants appeared in the ensuing months. Maintenance of seedling records was thus facilitated. Losses were recorded frequently, usually twice a week, and when the temperature was excessively high observations were made at shorter intervals. Long periods of fair weather induced daily visits to the quadrats. Dead seedlings were removed and carefully inspected to determine the causes of mortality. At the start of the first season they were so tiny that often the use of the microscope was necessary. The recording instruments were also of great as. sistance in deciding on the diagnosis.

Weather instruments were visited daily. Regular readings were started on June 15 and were continued until September 15 . This period corresponds approximately with the frost-free season. The opening date is coincidental also, if the spring has been normal, with the ending of foliation on hardwoods. 


\section{HABITAT CONDITIONS, 1944 \\ General Climatic Conditions}

Records of the Meteorological Station at Duchesnay supply information on the general climatic conditions which prevail in the area where the present study was initiated. Although these records cover only a period of seven years, they are fairly representative when compared with long standing records of the nearest city, located about twenty-five miles away.

Precipitation data, together with maximum, minimum and mean monthly temperatures of the normal summer season, are given in Table 2 . For purposes of comparison, data for 1944 are also presented in Table 2.

TABLE 2

Tempertaure ( $\left.{ }^{\circ} \mathrm{F}.\right)$ and Precipitation (Inches) During the Summer Months at Duchesnay Meteorological Station

\begin{tabular}{|c|c|c|c|c|c|c|}
\hline \multirow{3}{*}{$\begin{array}{l}\text { Month } \\
\text { June }\end{array}$} & \multicolumn{2}{|c|}{ Temperature, } & ${ }^{\circ} \mathbf{F}$ & $\begin{array}{l}\text { Departure of } \\
\text { Mean Temp. } \\
\text { from Normal }\end{array}$ & \multirow{2}{*}{$\begin{array}{l}\text { Precipi- } \\
\text { tation, } \\
\text { Inches }\end{array}$} & \multirow{2}{*}{$\begin{array}{c}\text { Departure of } \\
\text { Precipitation } \\
\text { from Normal, } \\
\text { Inches }\end{array}$} \\
\hline & $\begin{array}{r}\text { Maximum } \\
70.1 *\end{array}$ & $\underset{48,4^{*}}{\operatorname{Minimum}}$ & $\begin{array}{c}\text { Mean } \\
59.2^{*}\end{array}$ & & & \\
\hline & $70.7^{* *}$ & $47.5^{* *}$ & $59.1 * *$ & -0.1 & $3.58 * *$ & -2.05 \\
\hline July & $75.4^{*}$ & $53.4^{*}$ & $64.4 *$ & & $5.29^{*}$ & \\
\hline & $76.0 * *$ & $52.6^{* * *}$ & $64.3 * *$ & -0.1 & $6.54 * *$ & $-1.2 \tilde{j}$ \\
\hline August & $73.4^{*}$ & $51.7 *$ & $62.5^{*}$ & & $5.31 *$ & \\
\hline & $77.2^{* *}$ & $53.4 * *$ & $65.3 * *$ & 2.8 & $5.03^{* * *}$ & -0.28 \\
\hline September & $64.1 *$ & $45.0^{*}$ & $54.5^{*}$ & & $5.38 *$ & \\
\hline & $65.5^{* *}$ & $46.8 * *$ & $56.1^{* *}$ & 1.6 & $5.98 * *$ & 0.60 \\
\hline Ave. for & $70.7 *$ & $49.6^{*}$ & $60.1^{*}$ & & $5.40 *$ & \\
\hline $\begin{array}{c}\text { season } \\
\text { * Station }\end{array}$ & $\begin{array}{c}72.3^{* *} \\
\text { normal, }\end{array}$ & $\begin{array}{l}50.1 * * \\
\text { year reco }\end{array}$ & $61.2^{* * *}$ & 1.05 & $\begin{array}{l}5.28^{* *} \\
* * 194\end{array}$ & -0.12 \\
\hline
\end{tabular}

As can be seen from Table 2, the summer season at Duchesnay is rather cool and rainfall is high and well distributed. In 1944, temperature was slightly above normal and rainfall, although not deficient, was somewhat lower than usual.

Further information relative to weather conditions in the experimenta! area during the summer of 1944 are set forth in Table 3.

TABLE 3

Condition of the Sky and Hours of Sunshine During the Summer Months (1944) at Duchesnay Meteorological Station

Number of Days

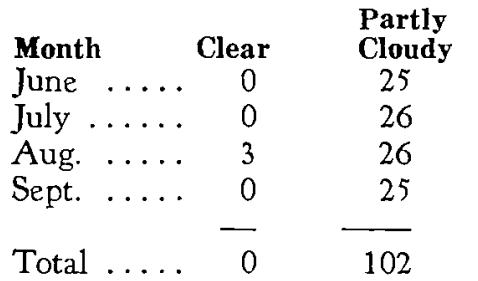

\section{Sunshine Hours}

With Total Cloudy Rainfall

5

5

2

5

17

13

16

13

12

$\overline{54}$
Percentage of

Possible No. of Hours

231.0

261.9

129.3
48.7

48.0

59.0

34.0

47.4 
The atmospheric phenomena here presented were reflected in the development of the vegetation as well as in certain soil factors, including temperature and moisture. Charts illustrating these factors on a weekly basis (see Appendix) give a much better idea of inter-relationships of the climatic and edaphic factors.

Whereas climatic data as presented in the preceding paragraphs are mainly of interest when forest regions are compared, they do not by any means explain the development of a lower stratum of vegetation such as is represented by the small tree reproduction under the canopy of a forest. To this end, the instruments set up at the three sample areas were indispensable.

In Tables 4, 5, and 6, maximum, minimum and average temperatures for the growing season are presented for the three canopy conditions.

TABLE 4

Maximum Air Temperatures ( ${ }^{\circ} \mathrm{F}$.) at 3 Stations

During the Growing Season of 1944

Period

June 15 - July $15 \ldots \ldots \ldots \ldots$

July 16 - Aug. 15 ..........

Aug. 16-Sept. 15 .........

Seasonal Mean ............
Station I

(Full Canopy)

$$
74.8
$$

73.3

67.7

71.9

TABLE ;
Station II Station III 79.8 (Open)

81.5

72.8

78.0
74.4

77.1

71.5

74.3

Minimum Air Temperatures $\left({ }^{\circ} \mathrm{F}\right.$.) at 3 Stations

During the Growing Season of 1944

\section{Period}

June 15 - July $15 \ldots \ldots \ldots$

Station I (Full Can 53.8

53.4

51.4

Aug 16 . Sept 15 ...............

Seasonal Mean

ept.

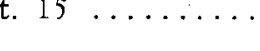

52.9

Station II

TABLE 6

Mean Air Temperatures ( ${ }^{\circ}$ F.) at 3 Stations

During the Growing Season of 1944

\section{Period}

June 15 - July $15 \ldots \ldots \ldots \ldots$

July 16-Aug. 15 ..........

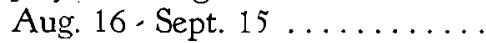

Seasonal Mean .............
Station I (Full Cano

63.3

59.5

62.4
Station II Station III 56.6

58.7

54.4

56.6

artial Ca

68.2

70.1

63.6

67.3

Station III
(Open)
52.7
54.9
50.3
52.3

52.3

It is to be noted that during the course of the entire growing season maximum air temperatures were consistently lower in the clear-cut than in the partially cut area. Normally, the reverse would be expected with the lowest temperatures at the station with the partial canopy. Similar observations were earlier made by Bates (1936) and Nägeli (1943) during investigations of the effects of windbreaks on local atmospheric conditions. They reported higher temperatures on the leeward than on the windward side of windbreaks. The explanation is that free air circulation in the open acceler- 
ates evaporation and lowers temperature, while stagnant air layers, as in forest stands with small openings, favor higher temperatures. At the station with a full forest canopy, maximum air temperatures were lower than in the open as would be anticipated; relatively low amounts of solar radiation penetrate the complete canopy.

\section{TABLE 7}

Average Range of Temperatures ( ${ }^{\circ} \mathrm{F}$.) at 3 Stations During the Growing Season of 1944

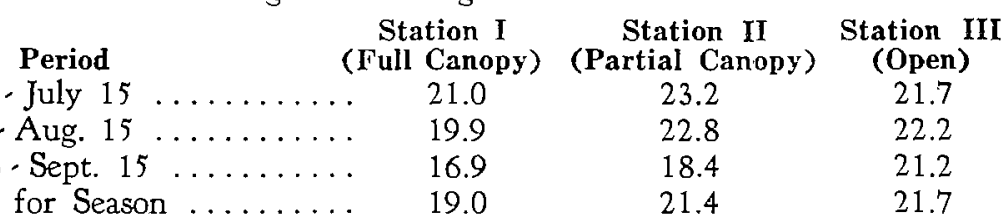

In spite of lower maximum temperatures at Station III than at Station II it can be seen from the data in Table 7 that the differences between minimum and maximum temperatures tend to increase as canopy density decreases; this is in good agreement with the findings of forest climatologists.

The season of 1944 as a whole did not show any appreciable abnormalties in the factors considered that might interfere with the normal development of tree seedlings. The last frost in the spring occurred a few days before June 15 and no damage was observed on the newly germinated seed. lings. In the fall the first freezing temperatures, recorded on September 23, 24, 25. and 27 at the Duchesnay Meteorological Station, did not adversely affect the vegetation. On occasional visits to the study area before the snow settled for the winter at the end of November, no apparent damage was detected.

\section{Solar Radiation Relationships}

Daily radiation intensities were determined throughout the season by means of paired black and white Livingston atmometer spheres under the three canopy conditions. The reservoirs were placed in wooden boxes above the ground line, a position which compares with that at which the foliage of young seedlings is displayed.

There is no need to justify the use of this type of atmometer, for several research workers, Burns (1927), Haig (1936), and others, have already demonstrated its value in ecological studies such as the present one. Differences of radiation intensity at the three stations were obtained by subtracting the amount of water lost by the white bulbs from that lost by the black bulbs.

The highest values obtained were, of course, at the station in the clearcut area where there was no obstacle to limit the loss of water from the porous cups. As incoming radiation is more and more obstructed by increasingly denser canopies, evaporation differences from the white and black bulbs tend to decrease. During periods when the sky is overcast, the difference in water loss from the atmosphere at the various stations is slight. 
TABLE 8

Mean Daily Evaporation in Milliliters from Spherical Atmometers at 3 Stations During the Growing Season of 1944

\begin{tabular}{|c|c|c|c|c|c|c|c|c|c|}
\hline \multirow{4}{*}{$\begin{array}{l}\text { Period } \\
15, \text { IIt } 15\end{array}$} & \multicolumn{3}{|c|}{$\begin{array}{c}\text { Station I } \\
\text { (Full Canopy) }\end{array}$} & \multicolumn{3}{|c|}{$\begin{array}{c}\text { Station II } \\
\text { (Partial Canopy) }\end{array}$} & \multicolumn{3}{|c|}{$\begin{array}{l}\text { Station III } \\
\text { (Open) }\end{array}$} \\
\hline & & White & & Black & White & & Black & & \\
\hline & & Bulb & Diff. & & & Diff & & Bulb & Diff. \\
\hline & & & & & & & & & \\
\hline & & 6.9 & 0.8 & & & & & & 9.40 \\
\hline & 4.23 & 3.56 & 0.67 & & & & 18.97 & 11.26 & 7.71 \\
\hline & 7.63 & 6.68 & 0.95 & 10.66 & 7.92 & 2.74 & 27.50 & 18.29 & 9.21 \\
\hline
\end{tabular}

The seasonal radiation intensity at the three stations, as computed from the data in Table 8, was as follows: Station III (open), 100 per cent; Station II (partial canopy), 29.7 per cent; and Station I (full canopy, 10.3 per cent. Several investigators, among whom are Wiesner (1907), Burns (1923), Bates and Roeser (1928), Grasovsky (1929), Shirley (1929, 1932), and Gast (1930, 1937), have set the minimum light intensity for survival of young seedlings at from 1 to 9 per cent; but it is conceded today that for ultimate survival much higher values are required. When adequate reproduction of a forest species is contemplated, it is not minimum but optimum environmental conditions which must be provided.

It may be observed that the highest radiation values were obtained during the period, June 15 to July 15. There was then a gradual decrease in the following periods. This is to be expected because of the gradual increase in the angle between the position of the sun at midday and the zenith as the season progresses and also because of the gradual decline in length of day. The decline in radiation intensity with seasonal progress was greater at the timbered stations than in the open area. Smith (1940) has properly ascribed this phenomenon to the fact that early morning light grows weaker in dense stands with a possible lowering of the period of effective radiation for plants living under canopies. The net result is likely to be stagnation of growth if not death for many higher plants; the final outcome may be inadequate reproduction.

Statistical analysis reveals highly significant differences between light values of timbered stations and the open, while medium significance exists between those for the timbered stations themselves.

Surface SoIl Temperature Relationships

On of the elements which has a bearing on satisfactory germination, growth and mortality of tree seedlings is soil temperature, as shown in the review of literature. This factor plays a prominent role in itself as well as through its influence on soil moisture.

Average soil temperature is believed to be of little significance in the study of growth and survival of small seedlings because it does not indicate the highly important extremes of temperature. It is, moreover, irrelevant in the detection of mortality causes.

Complete daily records of maximum surface temperatures both on litter and mineral soil were kept during the growing season of 1944 . Thermometers were placed near the ground-line and the bulbs were covered with one-half inch of surface material. 
TABLE 9

Mean Maximum Surface Temperatures ( ${ }^{\circ} \mathrm{F}$.) on Mineral and Litter Surfaces at 3 Stations During the Growing Season of 1944 $\begin{array}{ccc}\text { Station I } & \text { Station II } & \text { Station III } \\ \text { (Full Canopy) } & \text { (Partial Canopy) } & \text { (Open) }\end{array}$ Litter Mineral Litter Mineral Litter Mineral Period Surface Surface Surface Surface Surface Surface

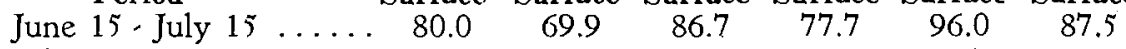

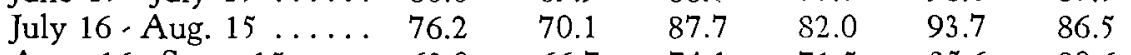

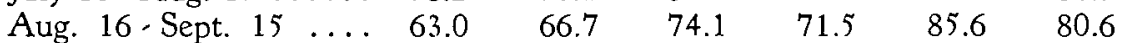
Seasonal Mean ....... $73.1 \quad 68.9 \quad 82.8 \quad 77.1 \quad 91.8 \quad 84.9$

Table 9 shows the daily maximum temperatures for the 1944 season. The three stations reveal substantial differences in the intensity of this factor, Seasonal means, for instance, indicate for litter a difference of 9.7 degrees F. between stations II and I and 9.0 degrees F. between Stations III and II. For mineral soil, these differences are 8.2 degrees $F$. and 7.8 degrees $F$., respectively. If differences between litter and mineral soil are considered, we obtain 4.2, 5.7 and 6.9 degrees F. at Stations I, II, and III, respectively.

Another characteristic of the three habitats is displayed when the range of maximum temperatures is considered (Table 10). Variations of soil temperatures at the stations supporting forest are less marked than in the open. It appears that in this respect the seasonal difference between Stations I and II is about 10 degrees F., whereas it is only 5 degrees F. between Stations II and III.

TABLE 10

Range of Maximum Surface Soil Temperatures ( ${ }^{\circ} \mathrm{F}$.) for 2 Surfaces at 3 Stations During the Growing Season of 1944

Station I Station II Station III (Full Canopy) (Partial Canopy) (Open) Litter Mineral Litter Mineral Litter Mineral

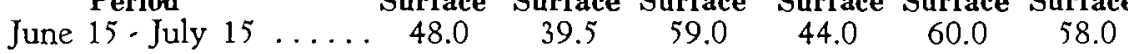
July 16 - Aug. $15 \ldots \ldots+42.0 \quad 18.5 \quad 53.5 \quad 35.0 \quad 52.0 \quad 31.5$ Aug. 16. Sept. $15 \quad \ldots \quad 23.0 \quad 18.0 \quad 28.5 \quad 27.0 \quad 45.0 \quad 28.0$ Seasonal Mean ....... $37.7 \quad 25.3 \quad 47.0 \quad 35.3 \quad 52.3 \quad 39.2$

It was noticed during the field work that litter consistently reached higher temperatures than mineral soil. Yet, after heavy rains, the reverse was fre. quently the case. The fact that the litter when dry reaches higher temperatures than mineral soil is explained by its lower specific heat. However, as litter and humus contain much more water immediately after heavy rainfall than mineral soil does, the specific heat of the organic matter is greatly increased compared to that of the mineral soil. The specific heat of water is several times that of litter, organic matter, or mineral soil when dry.

The highest surface soil temperatures registered during the 1944 growing season at the three stations are given in Table II. These temperatures were not frequently encountered. It is nevertheless quite possible that still higher ones have occurred, for thermometers were not available to cover adequately all parts of the plots. A high temperature of 134 degrees F. was registered, for instance, in a plot which is not included in the present study. 
TABLE 11

Highest Surface Soil Temperatures ( ${ }^{\circ} \mathrm{F}$.) Recorded at 3 Stations During the Growing Season of 1944

\begin{tabular}{|c|c|c|c|c|c|c|}
\hline \multirow[b]{3}{*}{ Period } & \multicolumn{2}{|c|}{$\begin{array}{c}\text { Station I } \\
\text { (Full Canopy) }\end{array}$} & \multicolumn{2}{|c|}{$\begin{array}{c}\text { Station II } \\
\text { (Partial Canopy) }\end{array}$} & \multicolumn{2}{|c|}{$\begin{array}{c}\text { Station III } \\
\text { (Open) }\end{array}$} \\
\hline & Litter & Mineral & Litter & Mineral & Litter & Mineral \\
\hline & Surface & Surface & Surface & Surface & Surface & Surface \\
\hline June 15 . July 15 & .105 & 91 & 120 & 97 & 120 & 114 \\
\hline July 16 - Aug. 15 & 104 & 79 & 119 & 100 & 122 & 101 \\
\hline Aug. 16-Sept. 15 & 80 & 75 & 91 & 89 & 110 & 95 \\
\hline
\end{tabular}

Lethal temperatures were encountered at all the stations; stem girdling, indeed, was noticed even at Station I. However dense the crown canopy of hardwood stands may be, "sun flecks" are likely to reach the soil.

It has been observed that losses ascribed to heat or insolation decreased on mineral soil with the reduction of canopy density (i.e., from Station I to Station III) and the reverse was the case for litter surface. This may be attributed to the fact that in the open the seedlings have built up a heat resistance as a consequence of their better development and sturdiness. On the other hand, a greater protection is afforded with an increasingly dense canopy. That is why if losses through insolation are encountered under such conditions they tend to be distributed more uniformly among seedlings of the two soil media.

Statistical analysis reveals interesting differences of temperatures at the three stations and for the two soil surfaces. (See Appendix).

\section{Surface Soll Moisture Relationships}

Soil moisture is undoubtedly an ecological factor of great importance which cannot be neglected in any study of initial establishment of forest seedlings. The surface layer of the soil is subject to substantial moisture variations in the course of a growing season, and the shallow-rooted plants are liable to suffer great losses from lack of available moisture.

Examination of the Duchesnay records already presented clearly show an abundance of precipitation at all seasons; but even in a region provided with this advantage protracted dry periods are likely to occur. Thus, in 1944 very little rain fell from June 26 to July 9 and from August 22 to September 1 (Table 13). Precipitations of July 5, August 26, and August 29 were too low to have any effect on the soil.

It is apparent that in this locality a dry period of more than a week is fatal to many seedlings when they are not older than a month or two. Regular readings of surface soil moisture at a depth of 0.5 inches in the summer of 1944 show that mineral soil surface was frequently near the field capacity. Moisture conditions in this medium never reached a critical stage at the level of measurement. Nevertheless, losses through lack of moisture were registered during the dry periods indicated. An examination of root penetration of the seedlings at that time revealed that the radicels had not gone down beyond the 
first quarter of an inch of soil, which was dry, while the electrodes were covered with half an inch of the material and at the latter level the soil was still moist.

Moisture conditions in the litter were definitely unfavorable during the same periods (Table 12). The few seedlings which had germinated in that medium were practically all eliminated at the full-canopy station as well as in the open.

TABLE 12

Soil Moisture Relationships at 3 Stations on 2 Surface Types During the Growing Season of 1944

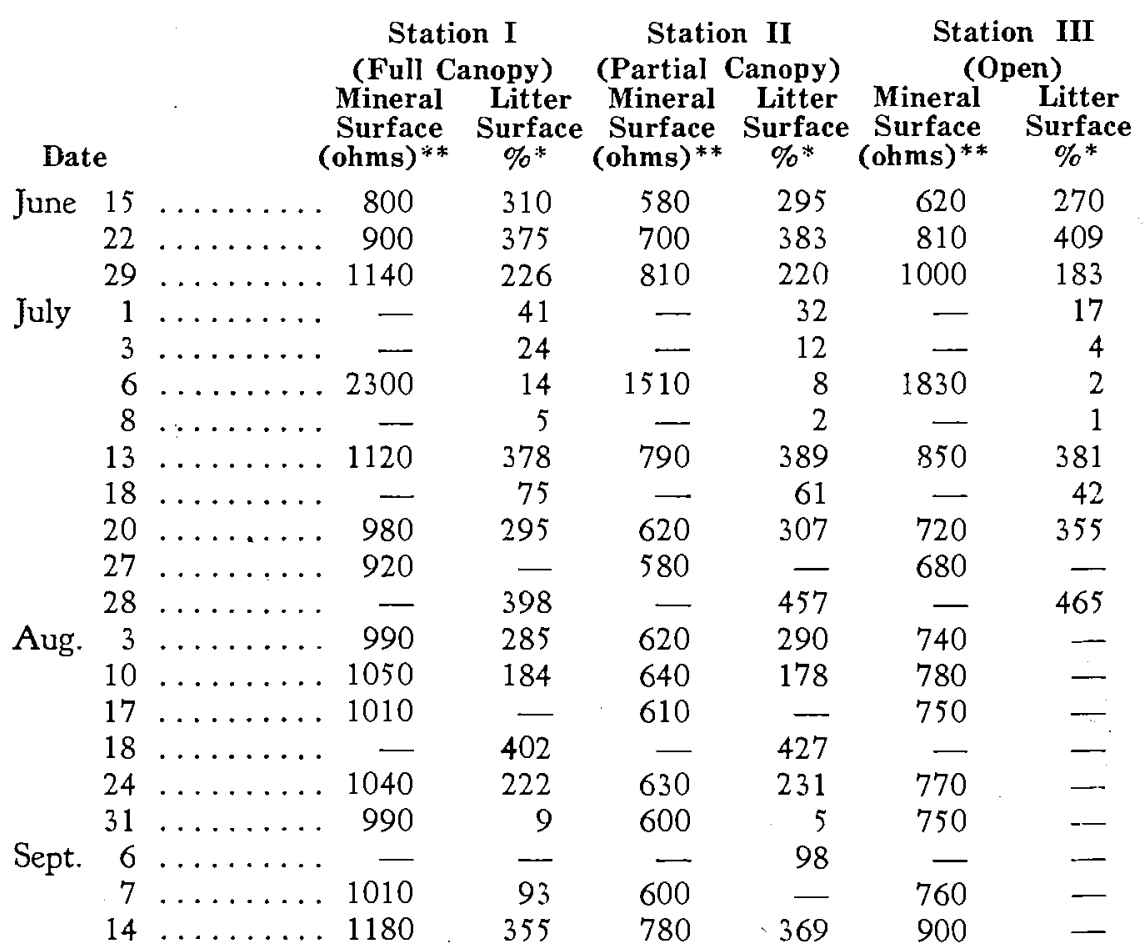

* Calculated as percentage of oven-dry weight of the sample.

** Electrical resistance measured with gypsum block electrodes; values below 60,000 ohms indicate available water in soil.

Mortality records indicate that however moist a growing season may be some of, the youngest seedlings will succumb from lack of water owing to unequal distribution of the precipitation. 
TABLE 13

Precipitation Record During the Growing Season of 1944

\begin{tabular}{|c|c|c|c|c|}
\hline Date & Inches & \multicolumn{2}{|c|}{ Date } & Inches \\
\hline & 0.42 & July & 30 & 0.28 \\
\hline 1 & 0.05 & & 31 & 0.69 \\
\hline 19 & 0.77 & Aug. & 4 & 1.46 \\
\hline 20 & 0.23 & & 5 & 0.27 \\
\hline 2 & 0.81 & & 9 & 0.06 \\
\hline $2 ?$ & 0.05 & & 14 & 0.17 \\
\hline 2 & 0.01 & & 16 & 0.31 \\
\hline July & 0.01 & & 17 & 1.31 \\
\hline s & 0.55 & & 19 & 0.03 \\
\hline 10 & 0.15 & & 20 & 0.09 \\
\hline 1 & 0.37 & & 21 & 0.53 \\
\hline 12 & 1.65 & & 26 & 0.05 \\
\hline 1 & 0.03 & & 29 & 0.02 \\
\hline 19 & 0.53 & Sept. & 1 & 0.14 \\
\hline 2 & 0.58 & & 2 & 0.99 \\
\hline 2 & 0.05 & & 6 & 0.01 \\
\hline $2 ?$ & 0.22 & & 7 & 1.24 \\
\hline 2 & 0.38 & & 8 & 0.55 \\
\hline 2 & 0.06 & & 9 & 0.02 \\
\hline 28 & 0.14 & & 13 & 0.42 \\
\hline $2^{\prime}$ & 1.58 & & 14 & 0.02 \\
\hline 29 & 0.51 & & 15 & 0.54 \\
\hline
\end{tabular}

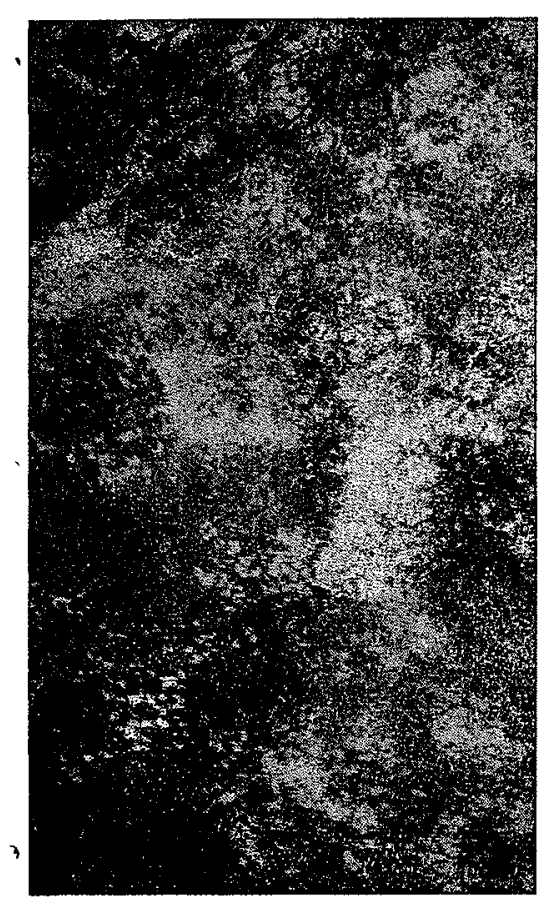

STATION 1

The Canopy. Full-shade Habitat. 


\section{HABITAT CONDITIONS, 1945 \\ General Climatic Conditions}

In 1945, the summer season did not differ essentially from the normal for the locality. Temperature was somewhat lower in June and July but it was higher in August and September in nearly the' same proportion. . Precipitation fell short of the normal by 2.3 inches in June but was considerably higher during the rest of the season.

TABLE 14

Temperature ( $\left.{ }^{\circ} \mathrm{F}.\right)$ and Precipitation (Inches)

During the Summer Months

at Duchesnay Meteorological Station

Departure of Departure of

Mean Temp. Precipi- Precipitation

Temperature, ${ }^{\circ} \mathrm{F}$.

$\begin{array}{lccllll}\text { Month } & \text { Maximum } & \text { Minimum } & \text { Mean } & { }^{\circ} \mathbf{F} \text {. } & \text { Inches } & \text { Inches } \\ \text { June } & 70.1^{*} & 48.4^{*} & 59.2^{*} & & 5.63^{*} & \\ & 68.8^{* *} & 47.5^{* *} & 58.1^{* * *} & -1.1 & 3.33^{* *} & -2.30 \\ \text { July } & 75.4^{*} & 53.4^{* *} & 64.4^{*} & & 5.29^{*} & \\ & 75.3^{* *} & 53.1^{* *} & 64.2^{* *} & -0.2 & 7.64^{* *} & 2.35 \\ \text { August } & 73.4^{* *} & 51.7^{*} & 62.5^{*} & & 5.31^{*} & \\ & 74.2^{* *} & 51.5^{* *} & 62.8^{* *} & 0.3 & 7.65^{* *} & 2.34 \\ \text { September } & 65.1^{*} & 45.0^{*} & 54.5^{*} & & 5.38^{*} & \\ & 64.8^{* * *} & 46.8^{* *} & 55.8^{* *} & 1.3 & 9.20^{* *} & 3.82 \\ \text { Ave. for } & 70.7^{*} & 49.6^{*} & 60.1^{*} & & 5.40^{*} & \\ \text { season } & 70.7^{* *} & 49.7^{* *} & 60.2^{* *} & 0.07 & 6.15^{* *} & 1.53\end{array}$

* Station normal, 7-year record.

*** 1945

Table 14 shows these facts in detail. If the 1944 and 1945 seasons are com. pared it is evident that the latter was consistently cooler; the monthly averages were from 0.1 to 2.5 degrees lower than in 1944. Rainfall was notably higher during the second season of observation. The difference amounted to 6.69 inches, yet it was distributed over a smaller number of days. During the two seasons during which the investigation was carried on, almost 50 per cent of the days were rainy.

TABLE 15

Condition of the Sky and Hours of Sunshine

During the Summer Months (1945)

at Duchésnay Meteorological Station

Number of Days

Sunshine Hours

Percentage of

$\begin{array}{ccccccc}\text { Month } & \text { Clear } & \text { Cloudy } & \text { Cloudy } & \text { Rainfall } & \text { Number } & \text { of Hours } \\ \text { June ...... } & 0 & 28 & 2 & 15 & 187.4 & 39.7 \\ \text { July ....... } & 0 & 29 & 2 & 15 & 254.7 & 53.7 \\ \text { August ..... } & 0 & 28 & 3 & 13 & 223.3 & 50.0 \\ \text { September . } & 0 & 21 & 9 & 14 & 140.7 & 37.0 \\ \text { Total .... } & 0 & 106 & 16 & 57 & 806.1 & 45.1 \text { (Ave.) }\end{array}$


Data relative to the number of hours of sunshine during the growing season of 1945 are presented in Table 15. Comparison of these data with comparable values for 1944 (see Table 3) indicates that there was slightly less sunshine in 1945 .

These differences in heat, moisture and light conditions were reflected at the stations of the study area. In Tables 16, 17 and 18, the maximum, minimum, and average temperatures at the three stations are presented.

TABLE 16

Maximum Air Temperature ( $\left.{ }^{\circ} \mathrm{F}.\right)$ at 3 Stations During the Growing Season of 1945

\begin{tabular}{|c|c|c|c|}
\hline Period & $\begin{array}{c}\text { Station I } \\
\text { (Full Canopy) }\end{array}$ & $\begin{array}{c}\text { Station II } \\
\text { (Partial Canopy) }\end{array}$ & $\begin{array}{l}\text { Station II } \\
\text { (Open) }\end{array}$ \\
\hline e 15 - July 15 & . 68.0 & 74.2 & 75.5 \\
\hline y 16 -Aug. 15 & 71.6 & 80.8 & 81.5 \\
\hline g. 16 -Sept. 15 & 66.5 & 70.9 & 73.7 \\
\hline Isonal Mean .. & 68.7 & 75.3 & 76.9 \\
\hline
\end{tabular}

TABLE 17

Minimum Air Temperatures ( ${ }^{\circ} \mathrm{F}$.) at 3 Stations

During the Growing Season of 1945

Period

June 15 -July 15 .....

July 16 -Aug. 15 .....

Aug. 16-Sept. 15 .....

Seasonal Mean .........

\begin{abstract}
Station I
\end{abstract}
Mean Air Temperatures ( ${ }^{\circ} \mathrm{F}$.) at 3 Stations

Station II

$$
54.6
$$

55.8

53.1

(Partial Canopy)
50.8

50.8

58.6

54.5

50.0

Station III
(Open)
51.4
48.7
48.7
49.7

During the Growing Season of 1945

Station I Station II

Period

June 15 -July $15 \ldots \ldots .61 .3$

July 16 -Aug. 15 ..... 63.7

Aug. 16-Sept. 15 .... $\quad 59.8$

Seasonal Mean .........
62.5

64.7

60.8

62.7

Station III
(Open)
63.4
65.1
61.3
63.3

\section{Station III}

63.4

61.3

63.3

It can be seen that, compared with 1944, maximum and average temperatures in 1945 were consistently lower for each month. A striking exception, however, is found at Station III. Here, during the first season, temperatures were lower than at the partial-canopy station. The soil surface was devoid of any vegetation on account of a clear-cutting operation during the previous fall. As explained earlier, these lower temperatures were due to free air circulation coupled with high evaporation rates. At the end of the 1944 season, however, a profuse growth of shrubs and seedlings became established in the clearing. As all measurements of temperature and evaporation were taken at the level of the soil, this new vegetation in 1945 acted as a windbreak causing air to be calm and warmer than in 1944 .

Table 19 presents the range of temperatures at the three stations in 1945. The data reveal larger variations in 1944, except at Station I. Al- 
though temperatures during the daytime were lower in 1945 than in 1944, the nights were also colder, thus accounting for the greater range in 1945 .

TABLE 19

Average Range of Temperatures ( ${ }^{\circ} \mathrm{F}$.) at 3 Stations During the Growing Season of 1945

\begin{tabular}{|c|c|c|c|}
\hline Period & $\begin{array}{c}\text { Station I } \\
\text { (Full Canopy) }\end{array}$ & $\begin{array}{c}\text { Station II } \\
\text { (Partial Canopy) }\end{array}$ & $\begin{array}{c}\text { Station I } \\
\text { (Open) }\end{array}$ \\
\hline 5 -July 15 & . $\quad 13.4$ & 23.4 & 24.1 \\
\hline 6 -Aug. $15 \ldots \ldots$ & 15.8 & 32.2 & 32.8 \\
\hline Sept. 15 & 13.4 & 20.2 & 24.8 \\
\hline for Season & 14.2 & 25.3 & 27.2 \\
\hline
\end{tabular}

At Station I the reverse situation was encountered, that is, the temperature range was greatest during 1944. The reason for a greater variation of temperatures here may be the fact that in 1944 the canopy was more open than in 1945, due to the activity of an insect which greatly reduced the foliage of trees. The solar radiation conditions tend to support this explanation.

Solar Radiation Relationships

Radiation intensities in 1945 were slightly different from those of 1944. The highest values were obtained during the period, July 16-August 15, at the partial-shade and full-sun stations. The season may be found in the fact that the number of hours of sunshine was much higher during this month than during the preceding one.

TABLE 20

Mean Daily Evaporation in Milliliters from Spherical Atmometers at 3 Stations During the Growing Season of 1945

$$
\text { Station I Station II Station III }
$$

(Full Canopy) (Partial Canopy) (Open)

Period Black White $\quad$ Black White Black White

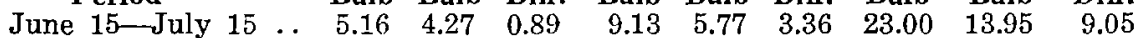
$\begin{array}{lllllllllll}\text { July 16-Aug. } 15 & \ldots & 5.56 & 4.96 & 0.60 & 12.33 & 8.30 & 4.03 & 30.86 & 19.16 & 11.70\end{array}$ $\begin{array}{llllllllll}\text { Aug. 16-Sept. 15 .. } & 3.79 & 3.11 & 0.68 & 6.91 & 4.87 & 2.04 & 21.07 & 12.47 & 8.60\end{array}$ $\begin{array}{llllllllll}\text { Seasonal Mean } \ldots . . . & 4.84 & 4.11 & 0.73 & 9.45 & 6.31 & 3.14 & 24.97 & 15.19 & 9.78\end{array}$

At Station I, the highest radiation intensity occurred during the period, June 15--July 15, and the lowest during the period, July 16-August 15. It may be suggested that the greater density of canopy in 1945 compared with 1944 accounted for this result. During the 1945 season, in fact, there was no defoliation by insects such as occurred during the summer of 1944. Table 20 gives the comparative daily insolation values as obtained from the Livingston atmometers. The seasonal mean indicates that in 1945 for Station I and Station II the solar radiation values were 7.4 per cent and 32.0 per cent of that at the full-sun station. This shows a slight decrease for Station I and a slight increase for Station II. The charts in the Appendix present the light relationships for the three stations. Heliograph values are also given in absolute number of sunshine hours. At the full-sun station an almost perfect agreement in trend between hours of sunshine and water loss from the atmometers is observed. 
Statistical analysis of the radiation and evaporation data indicates significant differences between the values for Stations I and II compared to those for Station III. Differences between data for Stations I and II are not significant at the conventional 5 per cent level by the slight margin of a fraction of a unit.

\section{Surface SoIl Temperature Relationships}

Variance shown in climatic factors and arising from lessened light and air temperature conditions in 1945 compared with 1944 are reflected in maximum surface soil temperatures. Monthly as well as seasonal mean maximum temperatures are noticeably lower. The lowest values were recorded at the full-canopy station but this is to be expected because the canopy was more nearly complete during the second season. Table 21 presents the relative temperature conditions at the three stations. Differences between seasonal means of Station I and Station II are 10.3 degrees F. and 9.1 degrees F. for litter and mineral soil, respectively. Between Station II and Station III these differences amount to 11.9 and 6.6 degrees $F$. for the same surfaces.

TABLE 21

Mean Maximum Surface Temperatures ( ${ }^{\circ} \mathrm{F}$.)

on Mineral and Litter Surfaces at 3 Stations

During the Growing Season of 1945

$\begin{array}{ccc}\text { Station I } & \text { Station II } & \text { Station III } \\ \text { (Full Canopy) } & \text { (Partial Canopy) } & \text { (Open) }\end{array}$

(Full Canopy) (Partial Canopy) (Open)

Litter Mineral Litter Mineral Litter Mineral

Period Surface Surface Surface Surface Surface Surface

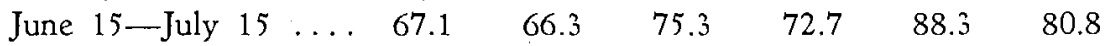

$\begin{array}{llllllll}\text { July } 16 \text {-A Aug. } 15 & \ldots & 72.7 & 69.4 & 86.5 & 81.1 & 97.7 & 85.6\end{array}$

$\begin{array}{llllllll}\text { Aug. 16-_Sept. } 15 & \ldots & 65.3 & 62.5 & 74.2 & 71.7 & 85.7 & 78.9\end{array}$

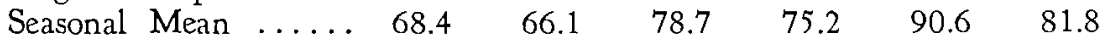

Another way of expressing the cooler conditions of the 1945 season is the range of maximum temperatures attained by the soil. These data are shown in Table 22. Comparison of the data in Table 22 with those in Table 10 reveals striking differences. On mineral soil, for instance, the seasonal range in 1945 was lower by $7.6,6.5$, and 9.1 degrees F. at Station I, II, and III, respectively.

TABLE 22

Range of Maximum Surface Soil Temperatures $\left({ }^{\circ} \mathrm{F}\right.$.) for 2 Surfaces at 3 Stations

During the Growing Season of 1945 Station I Station II (Full Canopy) (Partial Canopy) (Open) Litter Mineral Litter Mineral Litter Mineral

Period Surface Surface Surface Surface Surface Surface

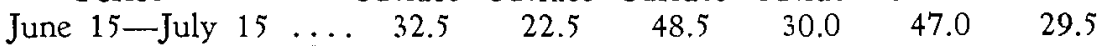
July 16-Aug. $15 \ldots \ldots \quad 24.0 \quad 14.0 \quad 47.0 \quad 30.0 \quad 44.0 \quad 23.5$

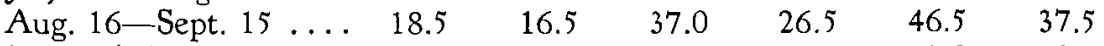
$\begin{array}{lllllll}\text { Seasonal Average } \ldots \ldots & 25.0 & 17.7 & 44.2 & 28.8 & 45.8 & 30.1\end{array}$

For litter surface, the values were: Station I, 12.7 degrees F.; Station II, 18.2 degrees F.; and Station III, 6.5 degrees F. The effect of a cool season on 
seedlings may mean lessened growth, but it also means reduced losses from high temperatures. On the basis of data presented in Table 23 it appears that during 1945 the soil thermometers recorded 118 degrees $F$. as the highest temperature and this maximum was encountered only once. Losses from insolation were accordingly very low at all the stations in 1945. It is true that the one-year old seedlings must in general have developed heat resistance, yet many of them at all the stations were still very small.

TABLE 23

Highest Surface Soil Temperatures ( ${ }^{\circ} \mathrm{F}$.)

Recorded at 3 Stations

During the Growing Season of 1945

Station I Station II Station III

(Full Canopy) (Partial Canopy) (Open)

Litter Mineral Litter Mineral Litter Mineral

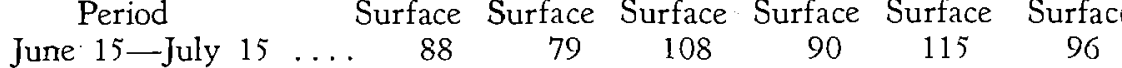

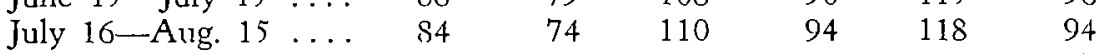

$\begin{array}{lllllll}\text { Aug. } 16 \text { - Sept. } 15 \ldots & \ldots 5 & 72 & 97 & 86 & 107 & 97\end{array}$

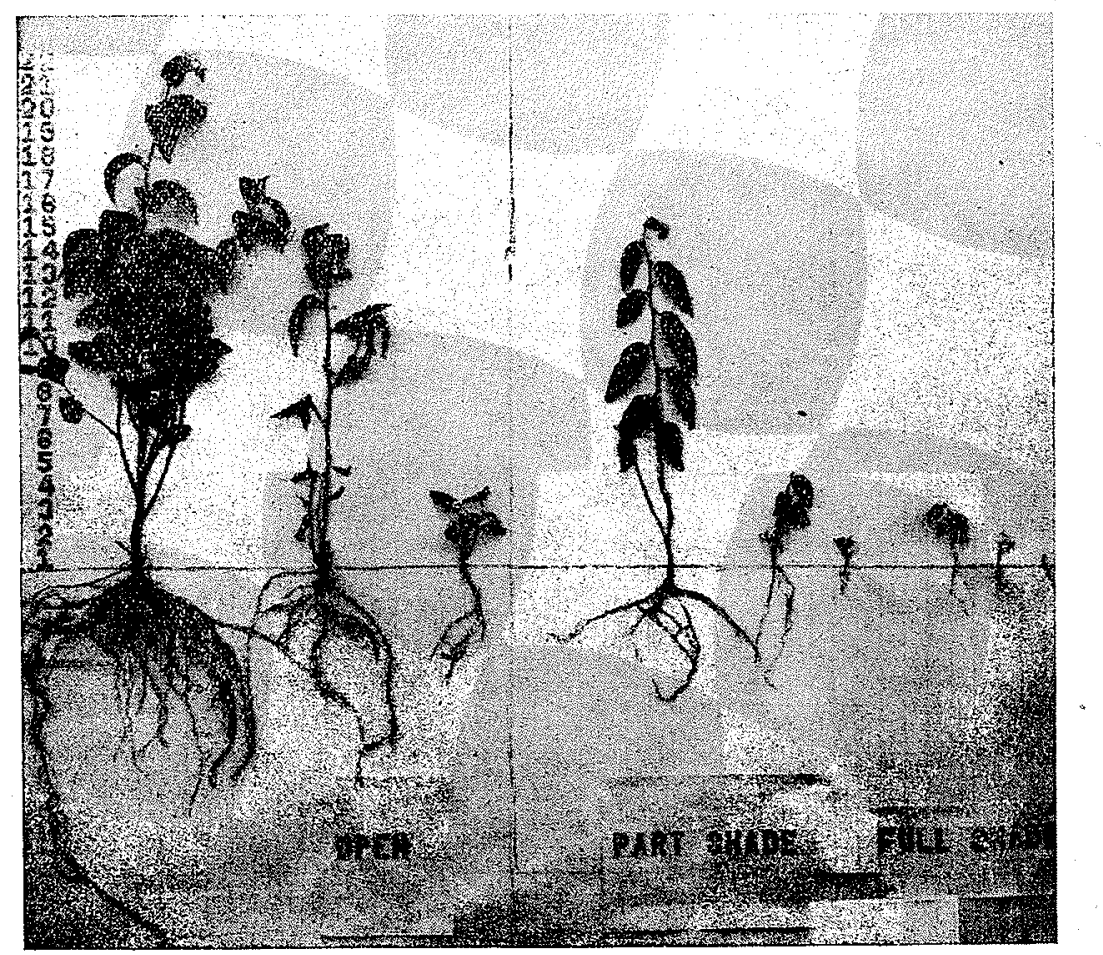

Roat and Top Development of Yellow Birch Seedlings at the Three Stations. Seedlings shown represent Maximum, Average, and Minimum Sizes reached at each station at the end of 1945 . 


\section{Surface Soll Moisture Relationshics}

During the 1945 season, soil moisture never reached a critical stage at the depth of measurement. In fact, the greatest interval between two rainfalls was never more than eight days and usually it was much less than this, as shown by the data in Table 25. The litter layer became very dry between June 25 and July 6 and also between August 16 and 24 at Station II. By this time, however, the seedlings had their roots well down in the humus layer and no loss was recorded. As no seedlings had survived in the litter at Station I and Station III during the growing season of 1944, moisture measurements for this medium were confined to Station II.

TABLE 24

Soil Moisture Relationships at 3 Stations on 2 Surface Types

During the Growing Season of 1945

Station I

(Full Canopy)

Mineral

Surface

Date (ohms) **

June $15 \ldots \ldots .1000$

$23 \ldots \ldots .850$

$29 \ldots \ldots .830$

Station II
(Partial Canopy)
Mineral

opy)

Surface Surface

(ohms)**

540

630

560

July $\quad 4 \ldots \ldots .910$

560

$6 \ldots \ldots, 1000$

650

$13 \ldots \ldots .790$

700

$20 \ldots \ldots \ldots 800$

550

530

Aug. $\quad 2 \ldots \ldots \ldots .96090$

620

$8 \ldots \ldots \ldots 1000$

680

$16 \ldots \ldots .1000$

$24 \ldots \ldots \ldots \quad 1250$

650

$30 \ldots \ldots \ldots \quad 1080$

725

780

610

720

(ohms)**

425

241

192

65

20

274

180

102

157

113

132

67

225

268

180
Station III

(Open)

Mineral

Surface

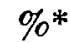

600

850

675

740

800

700

680

675

875

740

780

810

1030

850

830

* Calculated as percentage of oven-dry weight of the sample.

** Electrical resistance measured with gypsum block electrodes; values below $60,000 \mathrm{ohms}$ indicate available water in soil.

During the first and second season of growth definite moisture trends were observed at the three study areas. Consistently lower moisture readings were obtained at the full-canopy station than at the station in the open. This is in full agreement with the findings of Fricke (1904), Toumey (1929, 1931), Craib (1929), Fabricius (1929), and Barr (1930). Under the partial canopy, however, the soil surface retained much more moisture than at the other stations. Greatly reduced evaporation losses, coupled with lessened water depletion by surrounding trees due to their wider spacing must account for this favorable condition. 
TABLE 25

$\begin{array}{rrrr}\text { Precipitation } & \text { Record During the Growing Season of } & 1945 \\ \text { Date } & \text { Inches } & \text { Date } & \text { Inches } \\ \text { June } 15 & 0.53 & \text { July } 25 & 0.35 \\ 17 & 0.60 & 28 & 0.06 \\ 18 & 0.20 & \text { Aug. } & 0.81 \\ 19 & 0.15 & 3 & 0.20 \\ 21 & 0.19 & 4 & 0.04 \\ 22 & 0.01 & 10 & 0.04 \\ 23 & 0.24 & 13 & 0.12 \\ 25 & 0.06 & 15 & 0.77 \\ \text { July } & 0.11 & 17 & 0.48 \\ 3 & 0.02 & 18 & 0.28 \\ 6 & 0.32 & 21 & 0.03 \\ 7 & 0.26 & 26 & 1.45 \\ 8 & 0.33 & 27 & 0.12 \\ 10 & 3.14 & 28 & 0.25 \\ 11 & 0.10 & 31 & 1.32 \\ 12 & 0.12 & & \\ 13 & 0.36 & \text { Sept. } & 2 \\ 14 & 1.20 & 9 & 1.22 \\ 15 & 0.74 & 10 & 0.99 \\ 20 & 0.60 & 11 & 0.39 \\ 23 & 0.45 & 14 & 1.14\end{array}$

\section{SEEDLING GERMINATION AND MORTALITY RECORDS, 1944} COURSE OF GERMination

In view of the environmental conditions presented in the foregoing paragraphs, and with the aid of the analysis of variance of the pertinent data, the progress and final results of germination can be adequately explained. In general, the very beginning of the season was the best period for germination for the plants growing on mineral soil. This was true of Station I in particular where the tree cover very likely preserved soil moisture better than at any other period. Here 83 per cent of the germination took place during the month of May. In the clear-cut area germination during the same period amounted to 65 per cent. In June, high temperatures, together with less favorable moisture conditions, permitted germination of only 30 per cent in the same area. In view of its equally good conditions, germination at Station II in May should have been higher. However, June appeared to be as good if not better than the preceding month from the standpoint of germination. There is no question of low temperatures being a limiting factor for any of the stations. It may be suggested that with maintenance of favorable moisture conditions at Station II, the higher soil temperatures may have resulted in the slightly better germination during June.

A limited amount of seed germinated on mineral soil in July, August, and September at nearly all stations. 
TABLE 26

Germination by Months

for 2 Surface Types at 3 Stations

During the Growing Season of 1945

Station I Station II

Station III

(Full Canopy) (Partial Canopy) (Open)

\begin{tabular}{|c|c|c|c|c|c|c|}
\hline Period & $\begin{array}{l}\text { Litter } \\
\text { Surface }\end{array}$ & $\begin{array}{l}\text { Mineral } \\
\text { Surface }\end{array}$ & $\begin{array}{l}\text { Litter } \\
\text { Surface }\end{array}$ & $\begin{array}{l}\text { Mineral } \\
\text { Surface }\end{array}$ & $\begin{array}{l}\text { Litter } \\
\text { Surface }\end{array}$ & $\begin{array}{l}\text { Mineral } \\
\text { Surface }\end{array}$ \\
\hline May & 8 & 1746 & 270 & 1016 & 3 & 537 \\
\hline June & 32 & 318 & 194 & 1392 & 11 & 250 \\
\hline July & 3 & 2 & 44 & 36 & - & 11 \\
\hline August $\ldots$. & 80 & 37 & 46 & 12 & - & 15 \\
\hline September . & 14 & 0 & 4 & 3 & - & 11 \\
\hline Total & 137 & 2103 & 558 & 2459 & 14 & 824 \\
\hline
\end{tabular}

The course of germination in the litter was quite different. Except for the clear-cut area there was some germination during the entire season. It seems that in this medium germination is the result of fortuitous circumstances. The abrupt changes of moisture conditions which take place in this layer account for the scattered appearance of seedlings and their precarious existence. In the open, very rapid drying of litter confined germination to May and June with a final total of 14 seedlings. Due to lower evaporation rate of soil moisture, this factor of dryness of the medium operates to a lesser extent under the cover of the forest. In fact, eventually favorable moisture conditions in the course of the season permitted a limited number of seedlings to develop at the station under full forest cover.

Table 26 presents the monthly germination at the three stations for the two surface types. Statistical analysis of these data indicates significant differences between mineral soil and litter at all the stations. If mineral soil alone is considered, highly significant differences are revealed between Stations I and III and between Stations II and III. Lack of significant variances between germination of Stations I and II points to the beneficial effect of a canopy in reducing evaporation of soil moisture and transpiration rate and in permitting a large number of seeds to germinate. The poor results of germination obtained on litter at the three stations indicate that whatever the degree of cover, organic matter is clearly unreliable as a medium for germination.

In a recent study of germination and early survival of jack pine and black spruce, LeBarron (1941) states that germination responses in mineral soil, duff and other media correspond to the moisture holding characteristics and textures of the media. He found that mineral soil offered the least resistance to the transfer of water to the seeds, and undisturbed duff, the most; moreover, the former has the finest texture, which permits closer contact with the seeds and thus facilitates the transfer of moisture. For these reasons and others given previously, it is easily understood why germination of yellow 
birch is poor and inadequate in litter. It can be said also that because of the small size of yellow birch seed compared with that of the maples, its keenest competitors, the reserve food is proportionately low and, with the incidence of adverse conditions, the tiny embryo dies before emerging.

Course of MORTAlity

Soon after their germination, many seedlings experienced unfavorable conditions. That losses are greatest during the initial vegetative period is to be expected in view of the fact that the young shoots are in a state of succulence and the seedlings have poorly developed root systems. Should the growing conditions remain unfavorable for some time, then the weakness of the seedlings is instrumental in their being eliminated, particularly as the summer season progresses. This is what happened at the full-canopy station. Here, after thirty days of growth, the seedlings were at most only half an inch high and the rootlets were only about one-quarter of an inch long. The most important losses were recorded at the different stations after several successive days with clear skies and without rain.

TABLE 27

Monthly Losses of Seedlings by Causal Agencies, in Percentage of Total Germination, at 3 Stations for 2 Surface Types During the Growing Season of 1944

Mineral Surface

Litter Surface

Station I Station II Station III Station I Station II Station III

June:

Heat $\ldots \ldots \ldots 7.6$

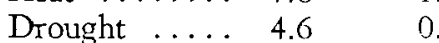

Insects $\ldots \ldots .0 .8$

July:

Heat ...... 5.5

Drought … 13.2

Mech. Injuries 12.5

Insects $\ldots \ldots \quad 3.9$

Rodents .... 7.0

August:

Heat ...... 0.4

Drought .... 0.6

Mech. Injuries 7.3

Insects $\ldots \ldots .2 .4$

Rodents .... 3.2

1.2
0.3

1.7

$-$

2.1

7.2

$-$

0.1

2.19

0.7

4.4

\section{7}

5.0

$-$

3.6

21.4

$\overline{0.3}$

4.7

16.1

10.2

71.4

September:

Heat ....... -

Drought $\ldots . \quad 0.05$

$\begin{array}{lll}\text { Insects } \ldots \ldots & 0.2\end{array}$

Rodents ..... 0.2

-

-

5.1

\section{6}

0.4

0.1

0.04

0.4

October:

Drought .... 0.09

Insects ....... 0.05

Rodents ..... 0.05

$0.6-$

9.5

17.5

-

3.6

-

$-0.6 \quad-$

0.04

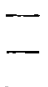

$-$

$=$

三

$-$

2.9

3.6

3.6

$-$

2.2

\section{3}


High temperature associated with dry soil surfaces are likely to be the main factors causing death in young seedlings of yellow birch. Losses through insolation were registered at all the stations as is indicated by the data in Table 27. Such losses were prevalent in the later part of June, at the beginning of July, and at the end of August. They correspond with the dry periods previously mentioned. At Station I, losses on mineral soil were slightly higher in June than during other months. It appears that on the litter surface the tiny seedlings received at first some protection from the shade given by the surrounding dead leaves. Not until August were losses recorded in this medium. At Station II high temperatures were responsible for the death of seedlings from June to September. A surface soil temperature of 120 degrees F. was recorded on July 6 and many plants succumbed that day on mineral soil as well as on quadrats with litter. The same occurrence, was noted between August 13 and 15. July was also the month of greatest losses in the open due to the same factor. In fact, a high tempera, ture of 120 degrees $F$. was attained at the soil surface during several days between July 1 and 9. Thereafter, losses were insignificant; only a few seedlings died in August and from then on all seedlings escaped, very probably because of their vigorous growth and the depth of their root penetration.

During protracted periods of clear days the level of soil moisture de. clined rapidly but was most noticeable in the litter surface. The litter ma. terial itself, as well as the underlying raw humus, underwent substantial losses of moisture owing to the large surface area exposed to evaporation. Further, this material was so porous that it did not provide for good contact with the plant roots, at least in their early development. Under these condi, tions the tree cover can have only a limited protective influence after several days without rain. A canopy may permit a shallow surface drying, whereas in the open the level of available moisture will be lower. Losses are then related to the respective root penetration of seedlings.

From the data in Tables 27 and 28 it appears that drought caused the death of a greater number of seedlings on the litter surface than on mineral soil. Losses were particularly important at the full-canopy and full-sun stations. The losses on litter surface amounted to 28.6 and 71.4 per cent, respectively; in the latter case it is questioned whether significance should be attached in the comparison of results since this percentage corresponds to the death of only ten seedlings. It is to be noted that, both on mineral and litter surfaces, losses from drought were recorded at Station I from June to September while in the other places they were confined to a shorter period. At Station III, in particular, July was practically the only month when lossses occurred. Here, the roots of the seedlings had penetrated to a depth varying between four and seven inches in the early part of August and occasional soil sampling revealed high moisture values at such level. The main losses from drought were generally recorded during the same periods as those occasioned by high temperatures. 
TABLE 28

Total Losses of Seedlings by Causal Agencies in Percentage of Total Germination at 3 Stations for 2 Surface Types

During the Growing Season of 1944

Station I Station II

(Full Canopy) (Partial Canopy) (Open)

Mineral Litter Mineral Litter Mineral Litter

\begin{tabular}{|c|c|c|c|c|c|c|}
\hline Period & Surface & Surface & Surface & Surface & Surface & Surface \\
\hline Heat $\ldots .$. & 13.5 & 9.5 & 9.8 & 12.9 & 7.0 & 28.6 \\
\hline Drought $\ldots$. & 18.6 & 38.6 & 6.5 & 12.4 & 4.8 & 71.4 \\
\hline Mech. Injuries & 19.8 & - & 0.1 & - & - & - \\
\hline Insects $\ldots \ldots$ & 7.6 & 19.0 & 0.4 & - & - & - \\
\hline Rodents & 10.4 & 7.3 & - & - & - & - \\
\hline tal & 69.9 & 74.4 & 16.8 & 25.3 & 11.8 & 100.0 \\
\hline
\end{tabular}

Mechanical injuries were responsible for the destruction of many seed. lings at the full-canopy station and to a much lesser degree at the partialcanopy station. These injuries are of two types: actual breaking at the stem due to the impact of heavy rain drops, and drying of the roots owing to their heaving up after disturbance of the material in their immediate vicinity. This last type of injury could have been designated as resulting from drought but it was classified as mechanical injury in view of the primary inducing cause. Naturally the losses were most prevalent among the weakest seedlings of Station I at times of heavy showers. They were, moreover, concentrated on the most heavily stocked quadrats on mineral surface. The scattered stem distribution on litter plots accounted for the immunity of the seedlings present and, besides, the litter layer itself acted as a protecting cover. In fact, not one seedling was lost on this medium at any of the stations. The heavy precipitations of July 12 and 27 and of August 4 and 17 caused the greatest damages. On these dates, 1.65, 1.58, 1.46, and 1.31 inches of rain were collected in the rain guages.

The biotic agencies which played an important role in the destruction of seedlings confined their activity almost entirely to the timbered areas. Red squirrels (Sciurus hudsonicus Erxl.) were repeatedly observed feeding amid the quadrats at the full-canopy station. No damage was recorded at Station II or Station III.

An insect, the spring cankerworm (Paleacrita vernata), which makes a frequent appearance in the region was noticed all through the season in the timbered areas. Its activity was greatest at the full-canopy station. Quadrats established on litter were the favorite place of activity for this insect. In the open area the insect was not entirely absent but did not cause the death of a single seedling. At the partial-shade station there was little damage on account of the greater spacing of trees and the resultant lesser concentration of food. Unidentified insects, active in decomposing the litter, also had a share in breaking up the leaf tissues of the tiny seedlings of Station 
I. Even though the insects did not entirely destroy the leaves their action may have been a factor in growth retardation, thus increasing the suscepti. bility of the plants to the adverse physical factors of the site.

Table 28 shows the comparative losses by agencies at the three stations. It appears that at the end of the season a very small number of seedlings survived under the full canopy. Losses were equally high on mineral and litter surfaces. At Station II, losses were higher on litter than on mineral surfaces, but to a much lesser extent than at Station I. In fact, on litter 7j per cent of the seedlings survived, while in the full-shade station losses amounted to this figure. On mineral soil, nearly 30 per cent were still alive at the latter station as compared with 71 per cent under partial canopy. The few seedlings which had germinated on litter in the open disappeared in the first half of the growing season, whereas on mineral soil only 12 per cent were destroyed.

\section{SEEDLING DeVELOPMENT}

Differences in microclimatic conditions which characterize the three habitats described in the foregoing pages no doubt manifest themselves in the relative losses suffered by yellow birch seedlings. They are also disclosed by the ability of the plants to grow in their respective habitats. In fact, at the end of the first season very great disparities were revealed among the seedlings, both in the height of the shoots and in the length of the roots.

TABLE 29

Average Height of Seedlings and Depth of Root Penetration At the end of 1944

\begin{tabular}{|c|c|c|c|c|c|}
\hline \multicolumn{2}{|c|}{$\begin{array}{c}\text { Station I } \\
\text { (Full Canopy) }\end{array}$} & \multicolumn{2}{|c|}{$\begin{array}{c}\text { Station II } \\
\text { (Partial Canopy) }\end{array}$} & \multicolumn{2}{|c|}{$\begin{array}{l}\text { Station III } \\
\text { (Open) }\end{array}$} \\
\hline $\begin{array}{l}\text { Height } \\
\text { (in.) }\end{array}$ & $\begin{array}{l}\text { Depth of } \\
\text { Roots } \\
\text { (in.) }\end{array}$ & $\begin{array}{c}\text { Height } \\
\text { (in.) }\end{array}$ & $\begin{array}{l}\text { Depth of } \\
\text { Roots } \\
\text { (in.) }\end{array}$ & $\begin{array}{c}\text { Height } \\
\text { (in.) }\end{array}$ & $\begin{array}{l}\text { Depth of } \\
\text { Roots } \\
\text { (in.) }\end{array}$ \\
\hline$\overline{0.97}$ & 0.50 & 2.10 & $\overline{1.40}$ & 6.40 & $\overline{7.80}$ \\
\hline \multicolumn{6}{|c|}{ Shoot-Root Ratio } \\
\hline & & & & & \\
\hline
\end{tabular}

Table 29 makes evident the poor showing of seedlings under the dense canopy of Station I. The shoot-root ratio 1.94 indicates an unfavorable balance. At Station II, the seedlings attained more than twice the height shown at Station I. Roots were better developed although occupying a superficial level. The seedlings of the clear-cut area were quite different. They grew to a height of more than 6 inches. Their roots were well anchored at a level where moisture is not wanting. As early as the end of July not one seedling was lost through lack of moisture. Thus, at the close of the first season, it can be seen that yellow birch is able to thrive in open stands or in clear-cut areas. 


\section{SEEDLING MORTALITY RECORDS AND SURVIVAL, 1945 COURSE OF MORTALITY}

The outstanding cause of mortality in 1945 was the extensive killing by late frosts at the outset of the season. At the beginning of spring a long period of warm weather melted a great part of the snow. On April 12 it had entirely disappeared. During May the development of vegetation proceeded normally until successive late frosts occurred on June 3, 7, 9 and 10 with temperatures as low as $19,29,30$, and 29.5 degres F., respectively. Extensive damage was witnessed in the locality, particularly to the flowers of the fruit trees. The quadrats established the previous year in the study area were severely affected. Losses were found to be directly pro. portional to the density of the canopy and inversely proportional to the relative vigor of seedlings. At Station I, on mineral soil, 90 per cent of them were killed; at Station II the percentage was 66.6 and in the open it was 21.9. In absolute number, losses amounted to 564, 1363, and 159 seedlings. On litter, all the seedlings present were killed under the full canopy. At the partial-canopy station, losses amounted to 82.5 per cent or 345 trees. At two of the three replifications of the latter station the canopy was nearly as dense as that of Station I. Frost losses were accord. ingly high.

TABLE 30

Monthly Losses of Seedlings by Causal Agencies, in Percentage of Seedlings Present at 3 Stations for 2 Surface types During the

Growing Season of 1945

Mineral Surface

Litter - Surface

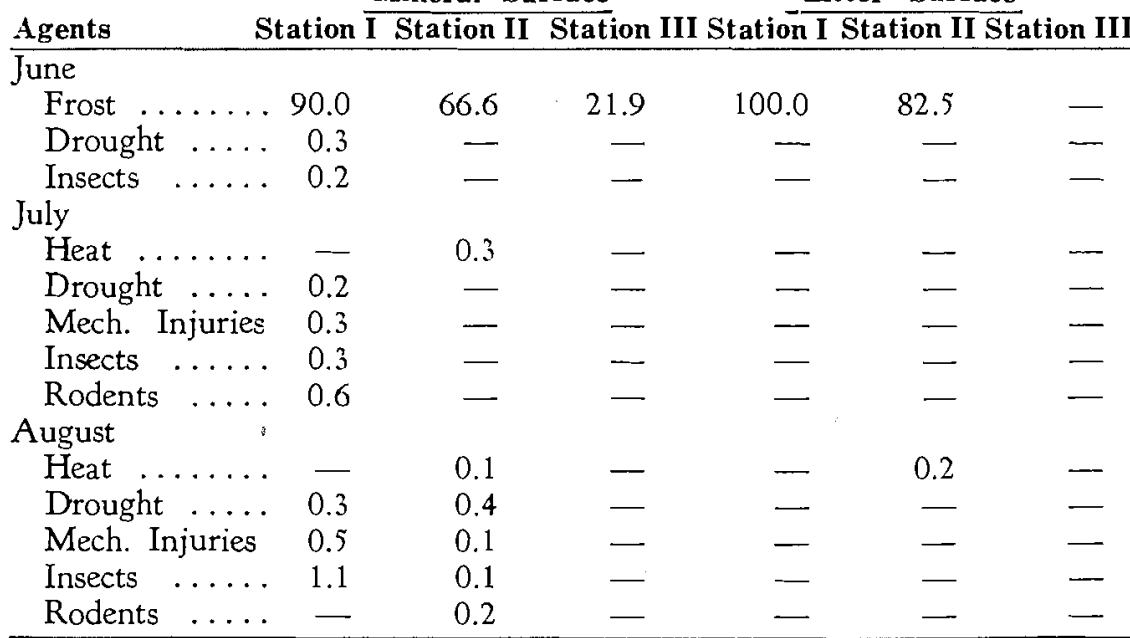

In the clear-cut area more plants were affected than the records actual. ly show. In many cases the main stem was killed and stood erect but shoots from dormant buds developed and a new leader started. This same feature was observed to occur to a lesser degree at Station II. The new branches that appeared grew vigorously thereafter, but in many instances did not 
reach the total height of the previous season. This faculty of sending out new shoots explains why mature yellow birch is quite frequently found as a multiple-stemmed tree. The common occurrence of multiple-stemmed trees itself indicates that late frosts at this latitude are common and are likely to damage many seedlings in the forests.

Most of the unthrifty plants which had survived the first growing season did not escape the frosts during early June. Therefore, following the late frosts only sturdy seedlings remained. Adverse site conditions during the second growing season affected a minimum number of seedlings because the population had previously undergone a rather rigorous selection.

No loss from any agency was recorded in the clear-cut area. At the partial-canopy station occasional mortality due to physical factors of the site was recorded. No seedlings died in June. In July only 0.3 per cent of the seedlings, located in the more open parts of the mineral soil quadrats, were killed by high temperature. No loss was recorded in June or July on litter. On August 25, after several days of high temperature, soil moisture fell close to the wilting cocfficient and a few shallow-rooted plants dried out. Only 0.4 per cent of the seedlings were affected. Losses came to a close for 1945 with 0.04 per cent of the seedlings damaged by heavy showers.

Trend of mortality at the full-canopy station was about the same as at the station in the clear-cut area. The only difference was that losses occurred from June to August but an equal number of seedlings were eliminated at each of the two stations. No losses from high temperatures were recorded and only 0.3 per cent of the plants died from lack of soil moisture. Mechanical injuries due to heavy rains were recorded in July and August and affected 0.7 per cent of the seedlings.

Damages by biological agencies were insignificant. The spring canker. worm killed 1.6 per cent of the seedlings under the full canopy and only 0.1 per cent at the partial-shade station. Squirrels, probably finding no more seeds to feed on, made infrequent visits to the quadrats and their depredations were limited to 0.6 per cent of the seedlings at the full-shade and 0.2 per cent at the partial-shade station.

TABLE 31

Mortality of Seedlings by Causal Agencies in Percentage of Seedlings Present at 3 Stations for 2 Surface Types During the Growing Season of 1945 Station I Station II Station III (Full Canopy) (Partial Canopy) (Open)

\begin{tabular}{lccccccc}
\multicolumn{1}{c}{ Agents } & $\begin{array}{c}\text { Mineral } \\
\text { Surface }\end{array}$ & $\begin{array}{c}\text { Litter } \\
\text { Surface }\end{array}$ & $\begin{array}{c}\text { Mineral } \\
\text { Surface }\end{array}$ & $\begin{array}{c}\text { Litter } \\
\text { Surface }\end{array}$ & $\begin{array}{c}\text { Mineral } \\
\text { Surface }\end{array}$ & $\begin{array}{c}\text { Litter } \\
\text { Surface }\end{array}$ \\
\hline Frost $\ldots \ldots \ldots \ldots \ldots \ldots$ & 90.0 & 100.0 & 66.6 & 82.5 & 21.9 & - \\
Heat $\ldots \ldots \ldots \ldots \ldots$ & - & - & 0.4 & 0.2 & - & - \\
Drought $\ldots \ldots \ldots \ldots$ & 0.8 & - & 0.5 & - & - & - \\
Mech. Injuries $\ldots \ldots \ldots$ & 0.8 & - & $(0.04)$ & - & - & - \\
Insects $\ldots \ldots \ldots \ldots$ & 1.6 & - & 0.1 & - & - & - \\
Rodents $\ldots \ldots \ldots \ldots$ & 0.6 & - & 0.2 & - & - & - \\
Total $\ldots \ldots \ldots \ldots \ldots$ & $\overline{93.9}$ & $\overline{100.0}$ & $\overline{67.8}$ & $\overline{82.7}$ & $\overline{21.9}$ & - \\
\hline
\end{tabular}


STATION 2

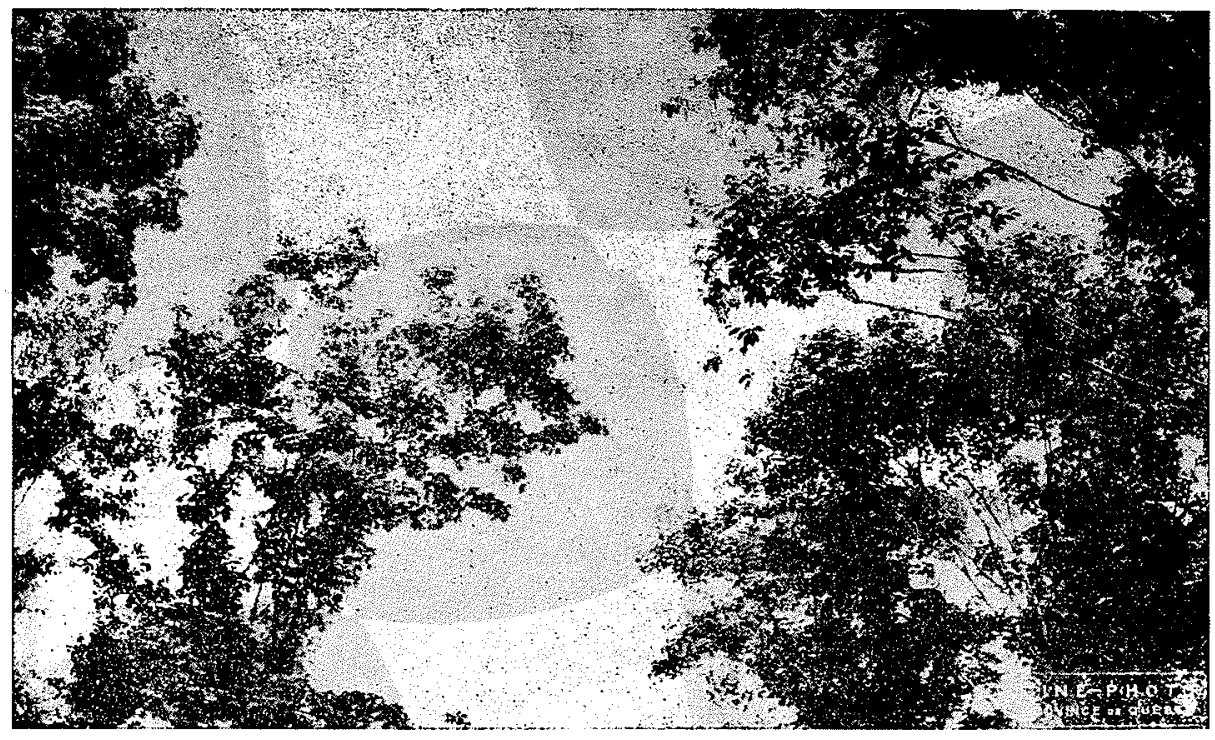

A-The Canopy. Partial-shade Habitat.

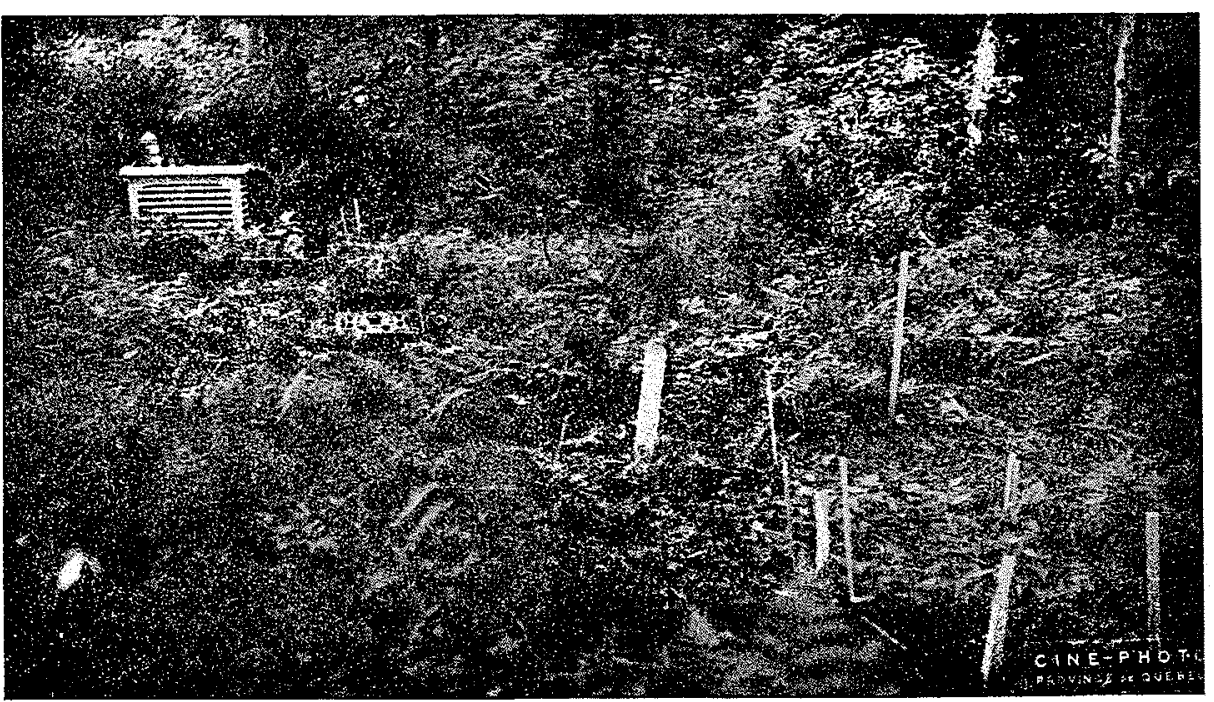

B-Instrumentation. Shelter for thermometers and thermograph; rain gauge; atmometer bulbs in circle; moisture bridge in the foreground. 
Table 31 presents the total losses based on the number of seedlings present at the beginning of the year. The most striking fact is the importance of the late frosts as a killing agent and a factor in survival. Only 30 per cent of the seedlings growing on mineral soil had escaped destruction in 1944 under the full canopy, and only about 6 per cent of the survivors were still growing at the end of the second season. On litter no seedlings were left after the late frosts. Under the more open canopy of Station II about 83 per cent of the seedlings which had germinated on mineral soil were still alive at the conclusion of the first growing season. This crop was reduced by more than two-thirds at the close of 1945. Of the 75 per cent which survived on litter in 1944 more than 80 per cent were killed during the second season. In the open only 12 per cent of the seedlings on mineral soil quadrats died in 1944; of the remaining plants nearly 22 per cent were killed during the second season.

\section{SeEding Survival}

A clearer picture of the situation is obtained if the losses of the two growing seasons are pooled and subtracted from the number germinating. Table 32 gives the resulis in absolute and relative values for the three stations and the two surface types. The differences are striking. The plots having mineral soil at the timbered stations started with a large number of seed. lings, three to four times greater than in the open. After two years of growth the seedlings at the open station outnumbered those at the fullcanopy station nearly fourteen times, whereas in the partial-shade area survival was only 1.1 times that of the open, with 90 more seedlings.

TABLE 32

Seedling Survival After 2 Growing Seasons Expressed in Terms of Absolute Numbers and Percentages of Total Germination

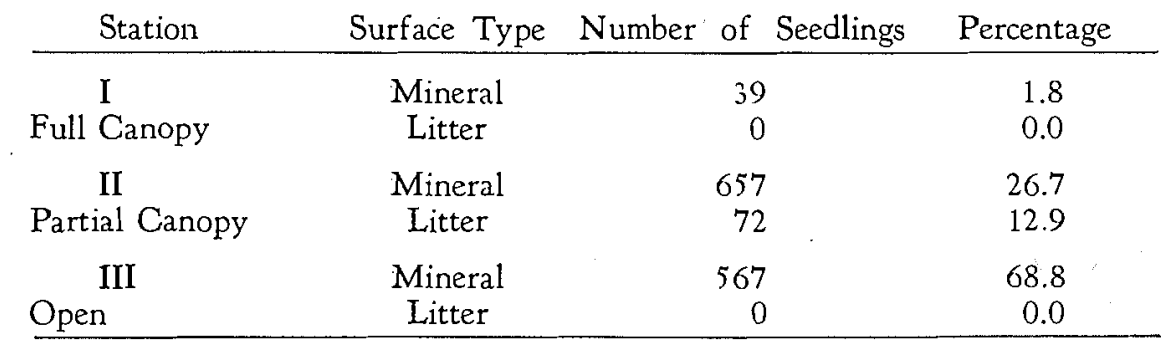

At the end of the second growing season the seedlings on litter surfaces in the open and under the full canopy had disappeared. At the partialshade station 12.9 per cent of the seedlings survived with a final total of 72 plants.

SeEding Development

No final conclusion can be drawn from the foregoing results as to just what crown-canopy density provides the best conditions for establishment of yellow birch. It is evident, however, that the desirable density is some, thing less than that provided by a full canopy. 
TABLE 33

Average Height of Seedlings and Depth of Root Penetration At the End of 1945

\begin{tabular}{|c|c|c|c|c|c|}
\hline \multicolumn{2}{|c|}{$\begin{array}{c}\text { Station I } \\
\text { (Full Canopy) }\end{array}$} & \multicolumn{2}{|c|}{$\begin{array}{c}\text { Station II } \\
\text { (Partial Canopy) }\end{array}$} & \multicolumn{2}{|c|}{$\begin{array}{l}\text { Station III } \\
\text { (Open) }\end{array}$} \\
\hline $\begin{array}{l}\text { Height } \\
\text { (in.) }\end{array}$ & $\begin{array}{l}\text { Depth of } \\
\text { Roots } \\
\text { (in.) }\end{array}$ & $\begin{array}{l}\text { Height } \\
\text { (in.) }\end{array}$ & $\begin{array}{l}\text { Depth of } \\
\text { Roots } \\
\text { (in.) }\end{array}$ & $\begin{array}{l}\text { Height } \\
\text { (in.) }\end{array}$ & $\begin{array}{l}\text { Depth of } \\
\text { Roots } \\
\text { (in.) }\end{array}$ \\
\hline \multirow[t]{3}{*}{1.47} & 1.18 & 3.52 & 3.17 & 10.86 & 12.77 \\
\hline & & Sho & Ratio & & \\
\hline & .18 & & & & \\
\hline
\end{tabular}

Table 33 shows that the seedlings in the open have three times the height of those under the partial-canopy and seven times that of the seedlings at the full-shade station. If root growth is considered, it is noticed that the roots of the seedlings at the partial-shade station have 25 per cent the length of those at the full-sun station, while those at the full-shade station have only 9 per cent. The shoot-root ratio at the same stations demonstrates the particularly favorable growing conditions which prevail in the open. Variations in height and root growth of the seedlings as affected by the relative light intensities existing at the three Duchesnay stations confirm earlier observations made elsewhere by certain workers, Lubimenko (1908), Shirley $(1929,1932)$. It is noted that the comparative seedling development shown above has been obtained on the mineral soil surfaces. The only seedlings which at the end of this investigation were still living on litter quadrats were found at the partial-canopy station. The performance of the plants on this medium was slightly better than that observed on the mineral soil quadrats at the same station. However, only 12.9 per cent of the seedlings which had germinated on litter were still alive at the end of the growing season of 1945 as compared with 26.7 per cent on mineral soil. Plate 5, in the Appendix, illustrates the relative development of the seedlings at the three stations.

\section{DISCUSSION OF RESULTS}

The three stations established at Duchesnay to study the factors affecting germination and early survival of yellow birch differed only in the density of the overwood cover. This factor accounted for large differences in the microclimatic conditions at the respective habitats. These differences in turn influenced considerably the course of germination, growth and survival of the seedlings artificially established for the purpose of this study. The two growing seasons during which the field work was carried out did not deviate appreciably from the normal for the locality. The first season was somewhat warmer than the second but in the course of the latter precipitation was higher and more evenly distributed. The brief dry periods which occurred in the summers of 1944 and 1945 emphasized the contrasting microclimates obtained in the clear-cut area and in the forest. 
Microclimatic factors which directly or indirectly affected germination were air and soil temperature, evaporation, solar radiation and surface soil moisture. As far as germination is concerned the tree cover, even without the presence of complete foliage, allowed a greater number of seedlings to germinate on mineral soil than in the open. In the latter area germination conditions were also favorable, there being plenty of moisture at the beginning of the season. However, the germination period was shorter because of a more rapid drying of the soil surface. At all three stations the litter surface proved to be a poor medium for the germination of yellow birch seedlings. This was particularly the case in the open where a very small number of seedlings germinated. Several workers, among whom are Moore (1922, 1926), Barr (1930), Haig (1936), Isaac (1943), and LeBarron (1944), obtained similar results. In general experience has proved, and it is the present consensus of opinion, that germination of tree seedlings on litter is possible only under especially favorable weather and site conditions or in the case of vigorous species.

\section{LOSSES Resulting fROM HeAt}

The first growing season is usually the most critical for the establishment of tree seedlings and yellow birch is no exception. The newly germinated plants are extremely small and weak and their root systems are quite superficial. Normally, the overhead shade of the old trees provides enough protection to the seedlings on the forest floor so that they are unlikely to suffer from the high temperatures of midsummer. This is logical and conforms to the findings of various research workers. But these investigators were not concerned with regeneration problems of hardwood species.

The shade cast by most conifers characteristic of Northern regions is greater and more evenly distributed than that of the hardwoods. Even in a dense yellow birch stand the irregularities of the thin foliage allow sunlight to reach the ground and tender shoots may suffer from high temperatures during periods of clear hot days. That is why losses accruing from this factor, although being slightly higher in the open, did not differ significantly from those in the timbered areas. The canopy, of course, afforded some protection to the seedlings. This explains the tendency of losses to be more uniformly distributed between the two surface types, mineral soil and litter. A peculiar trend was observed: losses on the mineral surfaces decreased with the introduction of more light on the soil. This can be ascribed to the lignified condition of the stem tissues and to the general sturdiness of seedlings in the open. It has already been mentioned that most of the losses took place during the first growing season. The records of 1944 show that high temperatures caused the loss of 11 per cent of the seedlings present. In 1945 very few seedlings died from heat injuries so this percentage is not appreciably modified.

Table 34 presents the comparative losses by causal agencies in percentage of the total losses during both seasons. It may be observed that heat was one of the main factors of mortality, being responsible for more than 14 per cent of all the losses sustained at the three stations. The trend in 


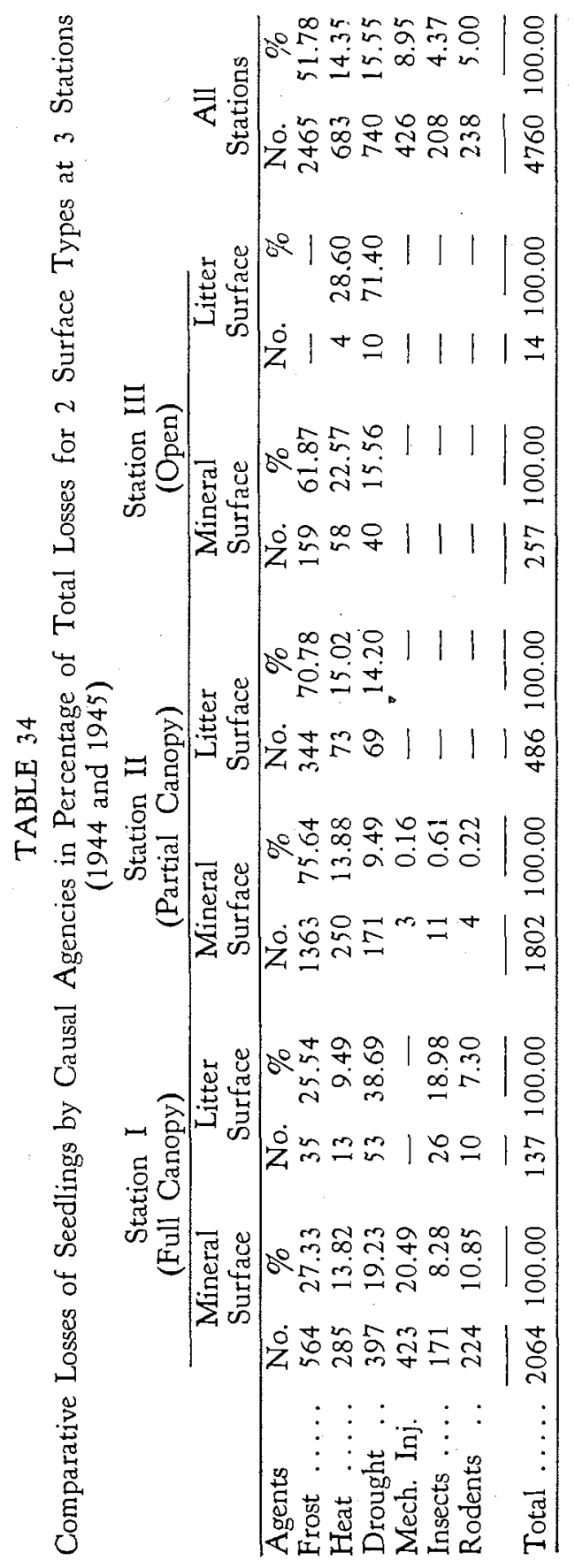


mortality from high temperature, as affected by exposure and type of seed bed was the same at Duchesnay as that observed by Haig (1936) at the Northern Rocky Mountain Forest Experiment Station, and by LeBarron in the Superior National Forest near Ely, Minnesota. The importance of heat as a factor causing mortality of seedlings on cutover areas points to the necessity of affording some protection to the young forests through the application of appropriate silvicultural treatments.

Losses ResultiŇg From Drought

The level of soil moisture declines more or less rapidly as the summer season advances. This decline is greatest under the canopy of a forest because transpiration losses by the overstory vegetation are great and because a substantial part of the precipitation is intercepted and thus prevented from reaching the soil. The lower evaporation at the surface of the soil under forest stands fails to compensate for these losses.

Surface soil moisture measurements during the seasons of 1944 and 1945 consistently revealed less moisture in the soil under the complete forest canopy than in the open. At the partial-canopy station, however, a better balance between water income and loss seems to have been established. The smaller number of overstory trees, together with the protective influence of the canopy, accounted for better moisture conditions. In the open, surface soil was intermediate in dryness compared with the other stations.

Losses through drought did not follow exactly the same pattern. They were governed by the type of seed bed and extent of root development. On mineral soil losses assumed less importance as the seedlings developed stronger and deeper roots. That is why so many seedlings on this medium in the open escaped drought. On the litter no significant differences were found between losses in the open and at the full-canopy-station. The seedlings had no time to develop on the litter surfaces in the open for they were killed during the first drought period. At the full shade station only a few seedlings germinated at a given time on account of wide variations in soil moisture and the failure of the medium to provide good contact with the roots. Losses from drought were equally distributed over all the months of the two growing seasons. Seedlings were enabled to establish themselves on litter only at the partial-shade station and losses from drought were significantly lower there than at the full-sun station. This cause of mortality was responsible for more than 15 per cent of all losses during 1944 and 1945 but the greater part of the loss was sustained during the season of 1944. No loss from drought was recorded in the open on mineral soil in 1945 due to the deep penetration of the seedling roots.

\section{Losses Resulting from Frost}

The frost in the fall of 1944 did not injure the seedlings at any of the stations. On the other hand, the late frosts of June, 1945, at a time when vegetation was in full development, caused serious injury to the young plants. Mortality because of frost accounted for more than 51 per cent of all the losses suffered at the three stations in the course of the two growing seasons. The percentages of seedlings destroyed on mineral soil under the fullcanopy, at the partial-canopy, and at the open station amounted to 90.0, 


\section{GERMINATION YELLOW BIRCH — LINTEAU}

66.6 and 21.9 , respectively; on litter they were $100.0,82.5$, and 0.0 . In the open all seedlings on litter had died at the beginning of 1944 from other causes than frost.

It thus appears that the severity of injury decreased with the decreasing density of the stand. At first thought this is inconsistent with expectations, in view of the presumed protective influence of the forest. Three possible explanations may be offered.

(1) Damages by frost are usually proportional to the age or size of the trees. Recovery from injury is normally easier for large trees because they have abundant reserves to draw on and more dormant buds with which to produce new shoots (Day and Peace, 1937). This would be the case with seedlings at Station III. Many injured plants developed new shoots after the old leader was killed. This mode of recovery was observed to a lesser extent at the partial-canopy station but not at all within the fullshade area. Moreover, completion of foliation on hardwood trees was concluded nearly three weeks after the first late frosts so that the forest did not afford as complete protection as it might had the frost occurred at a later date;

(2) in the clear-cut area the air may have moved freely from the nearest slope through the open forest where it settled so that the cold air mass did not stagnate over the clear-cut area;

(3) the proximity of a valley on the southern side of the timbered areas may have reduced the effectiveness of the canopy.

Of the three explanations offered the first is the least hypothetical. All the factors considered may have operated together. The fact remains that losses were found to be significantly different for the three stations, especially between Stations I and III, and II and III. Among the replications of Station II there are also significant variations in losses. It has been stated previously that two of the plots at Station II were located under a canopy the density of which closely resembled that at Station I. Seedlings in these plots were similar in vigor to those at the full-shade station.

Yellow birch is not usually regarded as a species which sprouts prolifically. However, it is suggested that the prevalence of multiple stems in this species can be traced to its possession in the seedling stage of dormant buds which are capable of producing new shoots when the seedling is killed back because of climatic or mechanical injuries. In a region of great variations of temperature, such as Quebec, late frosts are by no means infrequent. All the native birches show this multiple-stem form, which no doubt is practically ascribable to frost action.

The extent of the damage sustained by seedlings in the three study areas points to the silvicultural importance of frost and to the necessity of applying measures which may reduce frost incidence to the minimum compatible with a satisfactory development of the regeneration.

\section{Losses Resulting from Other CaUses}

Losses from mechanical injuries, rodents and insects were sustained at the full-canopy station almost exclusively. There, the low intensity of solar radiation available for plant growth resulted in the development of 
etiolated seedlings. This explains why a high proportion of the seedlings could not survive after being subjected to mechanical injuries or to the attacks of the spring cankerworm. Squirrels visited the seedling plots and destroyed relatively large numbers of plants. Those miscellaneous agencies accounted for nearly thirty-nine per cent of the losses sustained at the fullcanopy station during the two growing seasons. It is readily conceivable that even if these agencies had not taken their toll, adverse site conditions would have eliminated a large proportion of these seedlings.

Seedling Survival and Growth

The value of a silvicultural treatment designed to result in regeneration of a stand can be determined both by the vigor of the seedlings and the representation of the desired species. The present study has revealed interesting facts about germination, growth and survival of seedlings under three different degrees of overhead shade. The forest cover has a beneficial effect on germination, allowing a large number of seedlings to start. But as the summer progresses the frail plants, which have little reserve food, soon die if they are not enabled to enlarge quickly their aerial and underground parts. This is what happened at the full-canopy station. Less than 2 per cent of the seedlings were still alive after two growing seasons. Better moisture and light conditions at the partial-shade station resulted in survival of 39.6 per cent. In the full-sun area, where conditions for germination were less favorable, survival was much better, amounting to 68.8 per cent. Mineral soil was the best medium for survival. Slightly more than 12 per cent of the seedlings on litter surfaces escaped destruction at the partialshade station but there was no survival in the open or at the full-canopy area on the same type of seed bed. Thus, the stations, similar in their general site conditions but different in their microclimates, showed quite unlike per. centages of survival.

The stand on the area having a full canopy proved to be too dense to permit the establishment of an adequate number of seedlings. During 1944 and 1945 no seedlings appeared on the unseeded plots on mineral or litter surfaces. However, the study of the lesser vegetation showed the presence of a few yellow birches representing advance growth but they seemed to be slow-growing and unhealthy. On the other hand, red and hard maples were very abundant.

At the partial-canopy station 657 out of 2459 seedlings survived on mineral soil. On an acre basis this represents more than 30,000 plants, which is more than sufficient for good stocking. However, judging from the high rate of mortality during the growing seasons of 1944 and 1945 it is questionable whether even this stocking would result in a complete stand at maturity. The lesser vegetation survey made at the study areas revealed for Station II the presence of advance growth of both yellow birch and maples. The frequency * of the maples was 50 per cent and that of yellow birch, 30 per cent. All the records of the seeded and unseeded plots, and of the ground vegetation survey, indicate that the partial-shade station

* Frequency or "presence" 
STATION 3

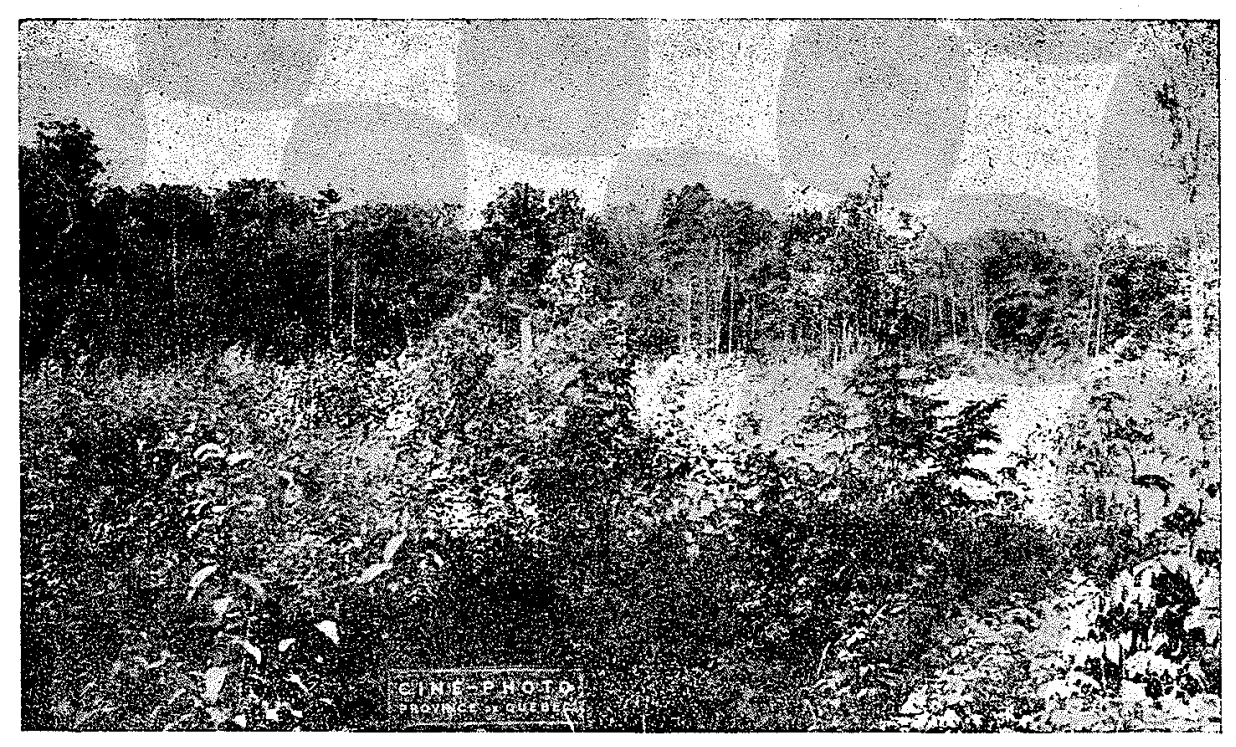

A-General view of the full-sun Habitat.

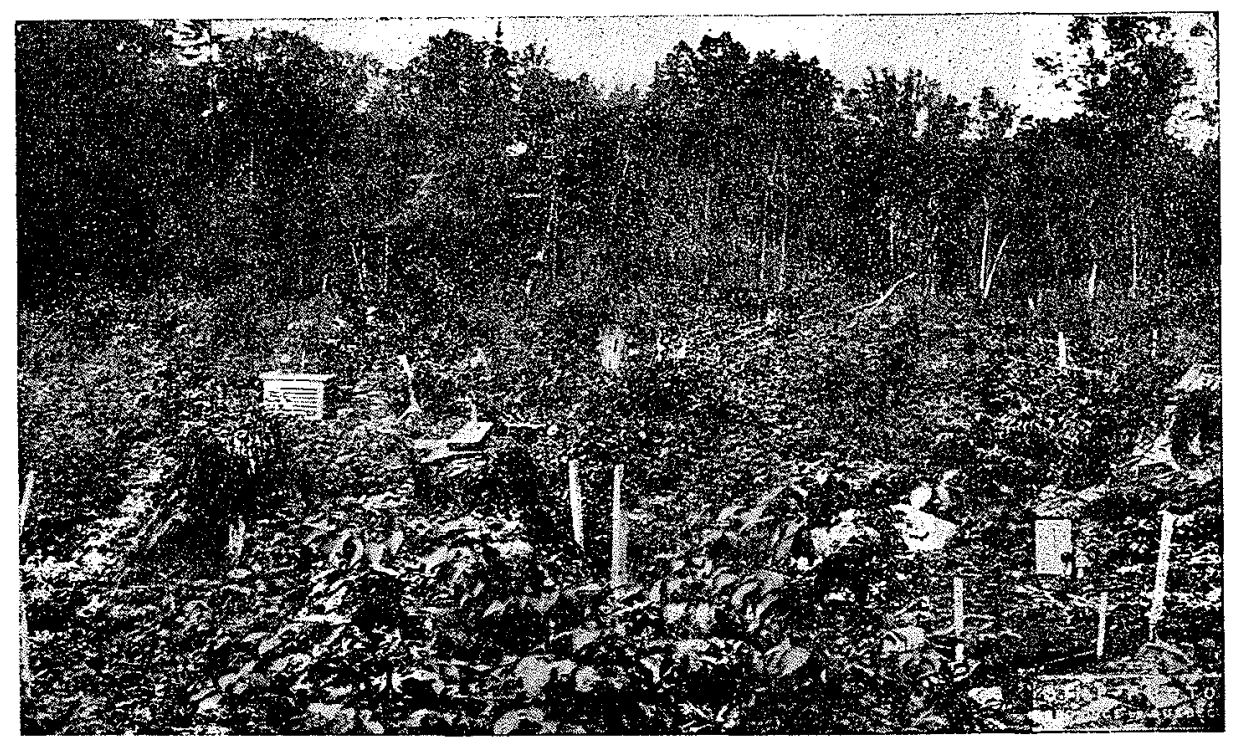

B-Close-up view of the above Station. 
is decidedly a better habitat for yellow birch than the full-shade station. The maple seedlings were found to be very abundant, representing nearly the entire advance growth at the full-canopy station, and they were present in considerable numbers even at the partial-shade station. Apparently thriving equally well in a mineral soil or in a litter seed bed, they offer keen competition to the other tree species, particularly yellow birch.

Germination records have shown a relatively small crop at the full-sun station compared to that at the partial-shade station. On the other hand, seedling survival was much better at the former than at the latter station. The litter surface in the open proved to be decidedly unfavorable for germination and survival of the seedlings on account of the rapid desiccation of the medium. No regeneration of any kind was found on the unseeded plots established in the center of the open area, but the lesser vegetation survey revealed a good stand of one and two-year old yellow birch seedlings located mostly at the margin of the area. The maples, abundant before the area was logged, were partly destroyed by the operation and were still scarce two years later.

The significant variances in survival between the three areas (Appendix: Statistical Analysis) indicate essentially different microclimates. These are further exemplified by the relative vigor of the surviving seedlings. At the end of 1945 seedlings attained an average height of 10.86, 3.52, and 1.47 inches at Stations III, II, and I, respectively. The height variances of the seedlings growing at the full-sun and timbered areas have been found highly significant. Thus, the clear-cut area furnished the best seedlings as well as the highest survival percentage. A lack of significance has been found in the height variances which exist between the two timbered areas. The vigor reached by the seedlings at the partial-shade station was not considerably greater than that at the full-shade station, but in this last case it was provided to an exceedingly small number of plants.

\section{SUMMARY AND CONCLUSIONS}

In the fall of 1943 three habitat stations were established at Duchesnay, Quebec, for the purpose of studying the factors affecting germination and early survival of yellow birch (Betula lutea Michx). The locality lies in the Algonquin-Laurentides section of the Great Lakes-St. Lawrence forest region. This section is within the limits of the so-called Northern Hardwoods region. The study area was located along a lower southwestern slope and the greatest distance between the stations was not more than one-quarter of a mile. Similar in aspect, drainage and soil conditions, the three habitats differed only in the density of the overwood. Initially the forest stand was similar over the entire area concerned in this investigation. One station was located in an uncut 70-year-old stand composed mainly of yellow birch and maple. An area treated with an improvement cutting which removed about 40 per cent of the stand volume provided the second station. A three-acre stand was clear'cut to establisk the third station.

An equal amount of yellow birch seed was sown at each station on eighteen quadrats representing two surface types, mineral soil and undisturbed litter. Eighteen unseeded quadrats established in the same conditions were 
also observed. Air temperature, relative humidity, maximum surface soil temperature, soil moisture, evaporation and light intensity were measured during two growing seasons at the three habitat stations. Determination of these environmental factors made possible an adequate study of germination, development and mortality of the seedlings. The weather conditions in the summer of 1944 and 1945 were sufficiently favorable to permit normal growth of the vegetation in the locality. However, the variation in density of the canopy at the three habitats gave rise to unlike microclimates. The main site factors which were affected were solar radiation, evaporation, air and soil temperature, and soil moisture. These conditions were reflected in considerable differences of germination, growth, and survival of the seedlings.

Seasonal solar radiation intensity values, determined in percentage of full sunlight in the clear-cut area, were approximately 10 per cent at the fullshade station, and 30 per cent at the partial-shade station in 1944; in 1945 they amounted to 7 per cent and 32 per cent, respectively.

Air temperature in the layer just above the soil surface averaged in 1944, 62.4 degrees $F$. in full shade, 67.3 degrees F. in partial shade; and 63.5 degrees $F$. in the open. The seasonal maxima were, in the same order: 71.9 degrees $F$., 78 degrees $F$., and 74.3 degrees $F$. In 1945 mean air temperatures at the same stations were as follows: 61.6 degrees $F$., 62.7 degrees $F$., and 63.3 degrees $F$. The seasonal maxima were 68.7 degrees $F$., 75.3 degrees $F$., and 76.9 degrees $F$. The lower values in the open compared with those of the partial-shade station in 1944 were traceable to a high soil evaporation caused by free air movement at the surface of the bare area. In 1945 luxuriant shrubby vegetation and tree reproduction established itself in the open and caused the air to be calm and usually warmer than at the partial-shade station.

The surface soil temperatures were higher than temperatures in the layer just above the soil owing to absorption of heat by the soil. In this connection, litter layer, due to its lower specific heat, reached higher values than mineral soil. Lethal high temperatures occurred more frequently in the open than under the forest canopy. No temperature of more than 122 degrees $F$. was recorded during the two growing seasons although a high of 134 degrees $\mathrm{F}$. was observed in the immediate vicinity of the open station.

Moisture conditions of the mineral surface soil were consistently better at the full-sun than at the full-shade station during the course of the two seasons. The best moisture conditions, however, were found at the partial. shade station. The factors which may have contributed to this situation are the protective influence of the tree cover and lower losses of moisture by evaporation. It is readily understood that the partial-shade station had an advantage not possessed by the clear-cut area: the tree canopy, by filtering solar radiation, induced lower surface soil temperature and water loss by evaporation. But the relatively smaller number of trees at the partialshade compared with that at the full-shade station was very likely responsible for reduced transpiration losses and consequent lesser depletion of soil moisture. 
Critically low moisture levels at the surface of the soil were recorded several times in the litter, during protracted periods of clear days. The amount of moisture present in this medium varied directly with density. of the canopy. Differences in the microclimate of the three stations were reflected in germination, development, and losses of the seedlings. The tree canopy undoubtedly favored lower losses of moisture at the beginning of the season due to its influence on temperature and evaporation. This factor accounted for the greater number of seedlings which germinated at the timbered stations as compared with the open. Litter possesses an unfavorable physical structure and is subject to big temperature and moisture variations. This situation was responsible for a very low germination of yellow birch, particularly in the clear'cut area. The average germination value per quadrat was 15 seedlings in full shade, 62 in part shade, and 2 in the open. On mineral soil, in the same order, the values were 233,273, and 92.

After two growing seasons, no seedlings remained on the litter surfaces except at the partial-shade station where survival amounted to 13 per cent of germination. Survival percentage on mineral soil was nearly 2 per cent in full shade, 27 per cent in partial shade, and 69 per cent in the open. The canopy density at the full-shade station was responsible for the slow growth of the seedlings, which, with weak roots and shoots, were unable to withstand adverse site conditions. At the partial-shade station the seedlings tended to be weak but this character was not as pronounced as at the station with the full canopy. The amount of light received at the partial-shade station was enough to allow a limited proportion of the seedlings to reach sufficient size and to attain vigor so as to become hardy. The better surface soil moisture conditions coupled with a satisfactory initial root growth allowed these seedlings to establish themselves in the humus layer at the partial-shade station. In the open the rapid height, diameter and root growth of the plants saved most of them from the injurious effects of high temperatures and lack of surface soil moisture as well as of the other unfavorable influences. The height reached by the seedlings at the end of 1945 in the open, partial-shade and full-shade stations was $10.86,3.52$ and 1.47 inches, respectively.

Seedling losses were relatively high during the first growing season. The main factors responsible were high surface temperatures, drought, mechanica! injuries, insects and rodents.

High surface temperature losses on mineral soil were linked with the relative vigor of seedlings. On litter they varied directly with the degree of exposure to light. Irregularities in the crown canopy of a hardwood forest where yellow birch predominates contrast with the conditions which prevail under the cover of a uniformly dense coniferous stand. This is the reason why heat losses were recorded at the full-canopy station. In 1944 such losses amounted to $13.5,9.8$ and 7.0 per cent of the seedlings present on mineral soil at the full-shade, partial-shade and open stations, respectively. On litter, losses were, in the same order, 9.5, 12.9 and 28.6 per cent. The lower limit of high temperatures fatal to young seedlings has been found by various workers to vary between about 122 degrees $F$. and 130 degrees F. 


\section{GERMINATION YELLOW BIRCH — LINTEAU}

Most of these investigations dealt with seedlings of conifers. It is believed that the lower limit of tolerance to heat for yellow birch lies below 122 degrees F. In 1945 losses due to this factor were negligible and occurred only at the partial shade station.

Drought was equally unimportant as a mortality factor in 1945 . During the first growing season drought was responsible for the death of 20 per cent of all seedlings in full shade, 7 per cent in partial shade and 6 per cent in the open.

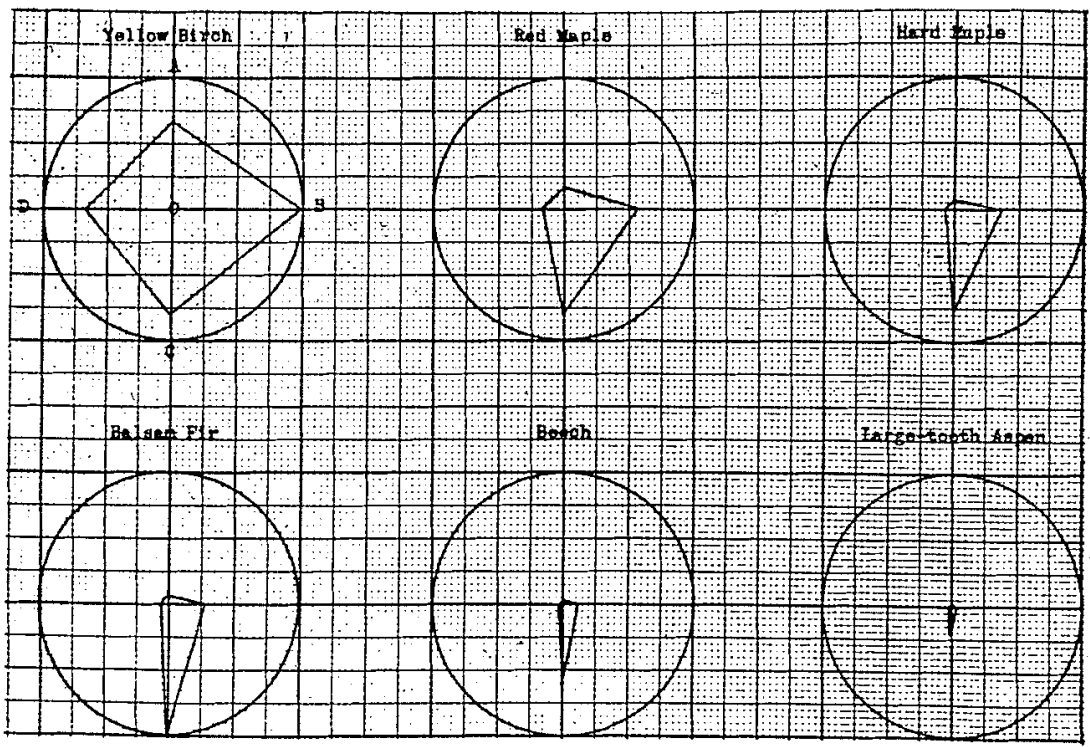

\section{PHYTOGRAPHS}

Showing the Place of the Main Species in the Composition of a Typical Yellow Birch-Maple Stand at Duchesnay Legend

AO: Abundance of dominant trees, i.e., those 10 inches, D.B.H., and over, in per cent (each division represents 5 per cent)

BO: Frequency of dominant trees (each division represents 5 per cent)

CO: Number of size classes in which the species is represented (four divisions represent a sime class).

DO: Basal area in square feet of dominant trees per acre (each division represents 10 square feet of basal area). Size Classes

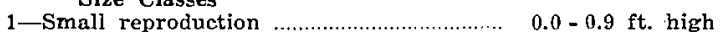

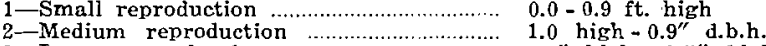
3-Large reproduction

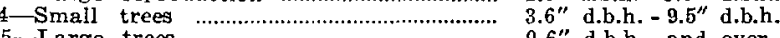

Late frosts were the main cause of seedling mortality. Freezing temperatures occurred in the early part of June, 1945, and accounted for 51 per cent of all losses suffered during the two growing seasons. Damage was most severe in the least vigorous seedlings; consequently losses were highest at the timbered stations and least in the open.

Biotic agencies limited most of their destructive activity to the full canopy station. The spring cankerworm destroyed nearly 9 per cent of 
the seedlings and squirrels injured more than 14 per cent at this station.

After the heavy frosts of early June no losses were recorded in the open in 1945 and very few were sustained at the timbered stations.

The present investigation concerning the factors affecting germination and early survival of yellow birch in Quebec leads to the following conclusions:

(I) The canopy of a yellow birch stand favors seedling germination by decreasing evaporation and extending the germination period. In a clear-cut area, at least on a warm aspect, the surface soil dries out rapidly and a smaller number of seedlings are likely to germinate in a given season.

(II) Hardwood litter is a poor medium for yellow birch germination due to its low specific heat and its unfavorable structure. Owing to slower drying of this medium under an overhead canopy, germination takes place more abundantly than in the open.

(III) It appears certain that the complete canopy of a yellow birch stand which intercepts between 90 and 93 per cent of total sunlight, prevents the normal development of the regeneration. The weak seedlings are readily susceptible to injury by a number of adverse site conditions and are doomed to die.

(IV) A partial canopy which permits about 30 per cent of sunlight to reach the soil surface permits large numbers of seedlings to become established but their development is slow and may require an undue extension of the regeneration period.

(V) In clear-cut areas a satisfactory number of seeds germinate and the seedlings become established without appreciable losses owing to their rapid growth. Establishment on litter is impossible, at least under the conditions of the experiment. The unfavorable environmental factors which prevail in litter seed beds during the period of germination tend to become even more unfavorable during the course of a growing season.

(VI) The first growing season is decisive in the establishment of yellow birch in the locality where the investigation was carried out.

(VII) In a region where late frosts are frequent, yellow birch seedlings are likely to suffer great damages if they have not developed hardiness through a vigorous development of the shoots and roots. In spite of the anticipated protective influence of the tree canopy, losses from frost were very important, desroying nearly 75 per cent of the seedlings present under the canopy. In the clear'cut area where the plants were tall and sturdy, only 22 per cent were lost by frost injury.

(VIII) Losses resulting from high temperatures and lack of soil moisture can be kept at a minimum if the best growing conditions are provided to the regeneration.

APPLICATION OF RESULTS IN SILVICULTURAL PRACTICE

Yellow birch is one of the few hardwoods in Quebec having a wide use and high market value. There are in the province large tracts of land where the species is found in variable amounts but the cutting of hardwood stands frequently results in unsatisfactory representation of yellow birch. These mature stands are either clear-cut over extensive areas, or the 
canopy is left almost intact. In the first case, shrubs and weed species very often invade the area and assume dominance, thus retarding or preventing the establishment of yellow birch. When the canopy is left intact, or opened only slightly through application of the single-tree selection system, regeneration of the maples is apparently favored. The present study sug. gests that conditions intermediate between these two extremes will favor the establishment of a greater number of yellow birch seedlings. If partial cutting is employed, the stand should be opened enough to allow at least thirty per cent of sunlight to reach the forest floor. This means cutting thirty to fifty per cent of he stand volume. Perhaps a better system would// involve clear-cutting in small patches of not more than one-half acre. The openings thus created would be favored with good light conditions and protection would be afforded by the surrounding trees. The use of clear-cutting in small units may actually become the equivalent of the group selection system. Restricting the size of the openings to one-half acre or less will help to keep shrubs and undesirable species in check. The smaller the group cut, the more completely the soil surface is likely to be torn up by a summer logging operation without any special effort to this end. Some reproduction will establish itself on the litter if preserved from long periods of direct insolation. Exposure of the mineral soil, however, undoubtedly constitutes a prerequisite to obtaining an adequate number of seedlings. The mechanical exploitation of the stands can be of great help in this respect.

If clear-cutting is used, lopping and scattering of the brush will be good practice because it will prevent the soil from drying out rapidly. Provided with this advantage yellow birch seedlings will have a chance to escape drought during the period when their roots are still superficial. Establishment of yellow birch regeneration can also be promoted in a clear-out area by cutting back the invading shrubs and weed species. Although some seed is stored in the humus layer and will germinate when the stand is opened, a better representation of the species will result if the regeneration cutting occurs in a seed year.

\section{LITERATURE CITED}

Adams, W. R. (1934) Studies in Tolerance of New England Forest Trees. $\mathrm{XI}$. The influence of soil temperature on the germination and development of white pine seedlings. Vt. Agr. Expt. Sta. Bul. 379. 18 p.

Baker, F. S. (1929) The effect of excessively high temperatures on coniferous reproduction. Jour. Forestry 27: 949-975.

Barr, P. M. (1930) The effect of soil moisture on the establishment of spruce reproduction in British Columbia. Yale Univ. School Forestry Bul. 26. $97 \mathrm{p}$.

Bates, C. G. (1924) Forest types in the central Rocky Mountains as affected by climate and soil. U. S. Dept. Agr. Bul. 1233. 52 p.

, and J. Roeser, Jr. (1924) Relative resistance of tree seedlings to excessive heat. U. S. Dept. Agr. Bul. 1263. 16 p.

(1928) Light intensities required for growth of coniferous seedlings. Amer. Jour. Bot. 15: 185-194. 
Bates, C. G. (1936) The windbreak as a farm asset. U. S. Dept. Agr. Farmers' Bul. 1405. 20 p.

Bouyoucos, G. J., and A. H. Mick (1940) An electrical resistance method for the continuous measurement of soil moisture under field conditions. Mich. State College Agr. Expt. Sta. Tech. Bul. 172. 38 p.

Briggs, L. J., and H. L. Shantz (1912) The wilting coefficient for different plants and its indirect determination. U. S. Dept. Agr. Bur. Plant Indus. Bul. $230.83 \mathrm{p}$.

Burns, G. P. (1916) Studies in Tolerance of New England Forest Trees. III. Discontinuous light in forests. Vt. Agr. Expt. Sta. Bul. 193. 22 p.

- (1923) Measurement of solar radiant energy in plant habitats. Ecology 4: 189-195.

- (1923) Minimum light requirement referred to a definite standard. Vt. Agr. Expt. Sta. Bul. 235. 32 p.

Burns, G. R. (1933) The long and short wave length limits of photosynthesis. Science 78: 130 .

Studies in Tolerance of New England Forest Trees VII. Leaf Efficiency in Thrifty and Stunted White Pine Seedlings. Vt. Sta., Bul. 267.

Cannon, W. A., and E. E. Free (1925) Physiological features of roots with especial reference to the relation of roots to aeration of the soil. Carnegie. Inst. Wash. Pub. 368. 168 p.

Craib, T. J. (1929) Some aspects of soil moisture in the forest. Yale Univ. School Forestry Bul. 25. 62 p.

Day, W. R., and Peace, T. R. (1937) Spring frosts. Imp. Forestry Inst. London. Forestry Com. Bul. 18. 131 p.

Ebermeyer, E. (1889) Einfluss des Waldes und der Bestandichte auf die Boden feuchtigkeit und auf die Sickerwassermenge. Allgem. Forst-u. Jagd-Zeit. 56: 1-13.

Egler, F. E. (1940) Berkshire Plateau vegetation, Massachusetts. Ecol. Monog. 10: 145.192.

Fabricius, L. (1929) Forstliche Versuche. VII. Neur Versuche zur Festellung des Einflusses von Wurzelwettbewerb und Lichtenzug des Schirm. standes auf den Jungwuchs. Forstwiss Centbl. 51: 477,506.

- (1929) Neuere Versuchsergebnisse zur Frage des Wurzelwettbewerbs und der Schattenfestigheit der Holzarten. Intern. Cong. Forestry Expt. Sta. Proc. 370-380. Stockholm.

Fricke, K. (1904) "Licht- und Schattenholzarten, ein wissenschaftlich nicht begründeted Dogma. Centbl. gesam. Forstw. 30: 315-325.

Fürst, H. von. (1905) Licht- und Schattenholzarten, ein wissenschaftlich nicht begründetes Dogma? Forstwiss. Centbl. 27: 1-10.

Gast, P. R. (1930) A thermoelectric radiometer for silvical research. Harvard Forest. Bul. 4. 76 p.

(1937) Studies on the development of conifers in raw humus. III. The growth of Scots pine (Pinus Silvestris L) seedlings in pot cultures of different soils under varied radiation intensities. Statens Skogsförsoksanst. Meddel. 29: 587-678. 
Graham, S. A. (1939) Principles of Forest Entomology. XVI 410 p. McGraw-Hill Book Co., Inc. New York and London.

Grasovsky, A. (1929) Some aspects of light in the forest. Yale Univ. School Forestry Bul. 23. 53 p.

Haig, I. T. (1936) Factors controlling initial establishment of western white pine and associated species. Yale Univ. School Forestry Bul. 41.149 p.

Halliday, W. E. D. (1937) A forest classification for Canada. Can. Dept. Mines and Resources. For. Service Bul. 89.50 p.

Hawley, R. C. (1922) White pine stands on experimental plots at Keene, N.H. Yale Univ. School Forestry Bul. 7. 33 p.

(1937) The practice of silviculture. XIV 252 p. John Wiley and Sons, Inc. New York.

Heimburger, C. C. (1941) Forest-site classification and soil investigation on Lake Edward Forest Expt. Area. Dom. For. Service Silv. Res. Note 66. Canada Dept. Mines and Resources.

Heyer, G. (1852) Das Verhalten der Waldbaüme gegen Licht und Schatten. 88 p. Erlangen.

Holch. A. E. (1931) Development of roots and shoots of certain deciduous tree seedlings in different forest sites. Ecology 12:259-298.

Holman, H. L. (1927) Natural regeneration of spruce in Alberta. For. Chronicle Vol. 3. Sept. issue.

Isaac, L. A. (1943) Reproductive habits of Douglas fir. Chs. Lathrop Pack For. Foundation, Washington, D.C. 107 p.

Jensen, V. S. (1938) Suggestions for the management of Northern Hardwood stands in the Northeast. Jour. Forestry 36: 957-961.

Kienholz, R. (1933) Frost damage to Red Pine. Jour. Forestry 31.392 p.

Knuchel, H. (1914) Spectrophotometrische Untersuchungen im Walde. Mitt. Schweiz. Centralanst. Forstl. Versuchsw. 11: 1.94.

LeBarron, R. K. (1944) Influence of controllable environmental conditions on regeneration of jack pine and black spruce. Jour. Agr. Research 68: $97-119$.

Lowdermilk. W. C. (1925) Factors affecting the reproduction of Engelmann spruce. Jour. Agr. Research 30: 995-1009.

Lubimenko, W. (1908) Production de la substance sèche et de la chlorophylle chez les végétaux supérieurs aux différentes intensités lumineuses. Ann. Sci. Nat. Bot. IX, 7: 321-415.

Lutz, H. J. (1930) The vegetation of Heart's Content, a virgin forest in Northwestern Pennsylvania. Ecology 11: 1-29.

McCarthy, E. F., and H. C. Belyea (1920) Yellow birch and its relation to the Adirondack forest. N. Y. State College Forestry, Syracuse Univ. Tech. Publ. 10. 50 p.

Mesavage, C. (1939) Frost damage to forests in northern New Jersey. Jour. Forestry 37: $345-346$.

Miller, E. C. (1931) Plant physiology, with reference to the green plants. XXIV 900 p. New York and London. 
Moore, B. (1922) Humus and root systems in certain northeastern forests in relation to reproduction and competition. Jour. Forestry 20:233-254.

- (1926) Influence of certain soil and light conditions on the establishment of reproduction in Northeastern Conifers. Ecology 7: 191.220 .

Münch, E. (1913) Hitzeschäden an Waldpflanzen. Naturw. Ztschr. Forst. u. Landw. 11: 557,562.

Nägeli, W. von. (1943) Untersuchungen über die Windverhältnisee im Bereich von Windschutzstreifen. Mitt. der Schweiz. Anstalt f. d. forst. Versuchswesen. Bands 1. Heft.: 223-276. Zurich.

Nichols, G. E. (1918) The vegetation of northern Cape Breton Island, Nova Scotia. Conn. Acad. Arts and Sci. Trans. 22: 249-467.

- (1935) The hemlock-white pine-northern hardwood region of Eastern North America. Ecology 16: 403-422.

Pearson, G. A. (1924) Studies in transpiration of coniferous tree seedlings. Ecology 5: 340-347.

(1929) The other side of the light question. Jour. Forestry 27: $807-812$.

(1930) Light and moisture in forestry. Ecology 11: 145-160.

Pfeiffer, N. E. (1928) Anatomical study of plants grown under glasses transmitting light of various ranges of wave lengths. Bot. Gaz. 85: 427.436.

Popp, H. W. (1926) A physiological study of the effect of light of various ranges of wave length on the growth of plants. Amer. Jour. Bot. 13: $706-736$.

Priestly, J. H. (1930) Studies in the physiology of cambial activity. III. The seasonal activity of the cambium. New Phytologist. 5: 316-354.

-..... L. I. Scott, and M. E. Malins (1933) A new method of studying cambial activity. Proc. Leeds Philos. Soc. Sct., 8: 365-374.

Rosé, E. (1913) Energie assimilatrice chez les plantes cultivées sous différents éclairements. Ann. Sci. Nat. Bot. IX, 17: 1-110.

Shirley, H. L. (1929) The influence of light intensity and light quality upon the growth of plants. Amer. Jour. Bot. 16: 354-389.

- (1932) Light intensity in relation to plant growth in a virgin Norway pine forest. Jour. Agr. Research 44: 227-244.

- (1934) Observations on drought injury in Minnesota forests. Ecology 15: 42.48.

(1936) Lethal high temperatures for conifers, and the cooling effect of transpiration. Jour. Agr. Research 53: 239-258. - (1943) Is tolerance the capacity to endure shade? Jour. Forestry $41: 339-345$.

Smith, L. F. (1940) Factors controlling the early development and survival of eastern white pine (Pinus strobus L.) in central New England. Ecol. Monog. 10: 373.420 .

Thornthwaite, C. W. (1931) The climates of North America. Geog. Review $21: 633.655$. 
Toumey, J. W. (1929) The vegetation of the forest floor; light versus soil moisture. Internatl. Cong. Plant Sci., Ithaca, N.Y., 1926, Proc. 1: 575-590. G. Banta Pub. Co., Menasha, Wisc.

, and R. Kienholz (1931) Trenched plots under forest canopies. Yale Univ. School Forestry Bul. 30.31 p. , and C. F. Korstian (1937) Foundations of silviculture upon an ecological basis. Second Edition. XIX 456 p. John Wiley and Sons, Inc. New York.

Veihmeyer, F. J., O. W. Israelsen, and J. P. Conrad (1924) The moisture equivalent as influenced by the amount of soil used in its determination. Univ. California Agr. Expt. Sta. Tech. Paper 16. 64 p.

Westveld, M. (1931) Reproduction of pulpwood land in the Northeast. U.S. Dept. Agr. Tech. Bul. 223.52 p.

Wiesner, J. (1907) Der Lichtgenuss der Pflanzen. 322 p. Leipzig.

Zederbaur, C. (1907) Das Lichtbedürfnis der Waldbäume und die Lichtmessmethoden. Centbl. gesam. Forstw. 33: 325-330.

Zillgitt, W. M., and F. H. Eyre (1945) Perpetuation of yellow birch in the Lake States forests. Jour. Forestry 43: 658-661.

Zon, R. (1904) Effects of frosts upon forest vegetation. For. Quarterly 3: $14-21$.

\section{APPENDIX}

Statistical Analysis

A number of important site factors were studied statistically to deter. mine their influence on the development of the seedlings established at the three habitat stations. The factors are solar radiation, evaporation and maximum surface soil temperature. Fisher's method* was adopted to determine significant variances between means. The analysis of variance outlined by Fisher and Wishart** and tabular values of F listed by Snedecor*** were used to determine significant differences in germination, growth and survival of seedlings at the three stations and on the two soil surface types. The same method was applied in the study of seedling losses caused by frost, heat and drought to determine the significant variances brought about by the differences in canopy density and soil surface types. After calculating the various constants, the degree of significance was indicated. A high degree of significance is related to real differences in the intensity of two factors.

Differences in solar radiation as well as in evaporation at the clear cut and timbered stations were found significant both in 1944 and 1945 (Tables 35 and 36). The failure of the timbered areas to show constant significance in their light values during the same periods is ascribable to irregularities in the light distribution as affected by the canopies. The fullcanopy and partial-canopy stations did not show significant differences in evaporation. This lack of significance emphasizes the protective influence of the tree cover at the two stations.

* Fisher, R. A. (1941) Statistical methods for research workers. Eight edition. Oliver and Boyd. Edinburg and London. $344 \mathrm{p}$.

- Fisher, R. A., and J. Wishart (1930) The arrangement of field experiments and the statistical reduction of the results. Imp. Bureau Soil Science. Tech. Com. 10. $24 \mathrm{p}$. * * Snedecor, G. W. (1934) Calculation and interpretation of analysis of variance and covariance. Collegiate Press, Ames, Iowa. $96 \mathrm{p}$. 
Maximum surface temperatures attained on litter were found to differ significantly from station to station. When the same factor is considered in relation to the two surface media, litter and mineral soil, significant differences were encountered only in the clear-cut area. As for maximum tempera. tures attained by mineral soil alone, there is lack of significance in the differences between the full and partial-shade stations. There is a medium significance between the latter and the clear'cut area, and a high significance between the full-shade and clear-cut area. These results hold true for both 1944 and 1945.

Variances in germination originating from stations and soil surfaces have been tested for significance. Both sources have been found to give significant results (Table 37). Litter gave significantly lower germination values than mineral soil at all three stations and was an equally poor medium under the forest and in the open. The moderate temperature variations and moisture retentiveness of mineral soil, partly due to the protective effect of tree cover, permitted a greater number of seedlings to germinate both at the full and partial-canopy stations than in the open. Differences which occurred were not, however, significant. Because of the fact that microclimatic conditions were quite different in the open from those in the forest, a significantly smaller number of seedlings germinated on the clear-cut area.

Drought as a cause of seedling mortality was found to be associated more with surface types than with stations (Table 38). At the timbered areas, no significance was revealed between loss variances on mineral and on litter surfaces. This was not the case for the clear'cut station. Although losses from drought on mineral soil quadrats were higher at the full-canopy than at the other stations, the differences encountered have not been found to differ significantly. On litter the only significant differences were between those suffered in the open and at the partialshade station.

Losses due to heat on mineral and litter surfaces at the clear-cut station varied significantly (Table 39). Mortality on litter was also significantly higher at the full-sun than at the full-shade station. On litter surfaces the losses increased with the progressive opening of the canopy. The reverse occurred on mineral soil; the relative losses were inversely proportional to the vigor of the seedlings.

Mortality due to late frosts was analyzed for mineral soil alone due to the absence of seedlings on litter at the full-sun station (Table 40). Losses caused by this agency were found to differ significantly between all the stations. Losses decreased from the full-shade to the open station and were clearly associated with the relative vigor of the seedlings.

Survival on litter was nil at the full-canopy and full-sun areas at the end of 1945 (Table 41); so it was analyzed for stations alone. Survival was lowest at the full-canopy station and highest in the open. Differences were found highly significant between all stations.

Average height of seedlings at the end of 1945 was also analyzed (Table 42). Differences are highly significant between timbered and clear-cut stations. The partial-canopy station, which had permitted a significantly higher survival than the full-shade station, failed to show significant height differences compared with the latter. 
I

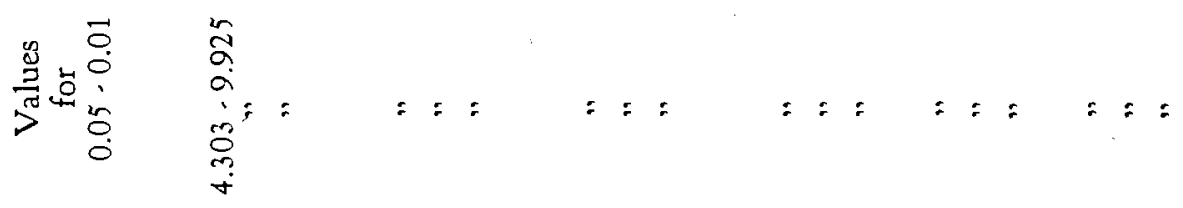

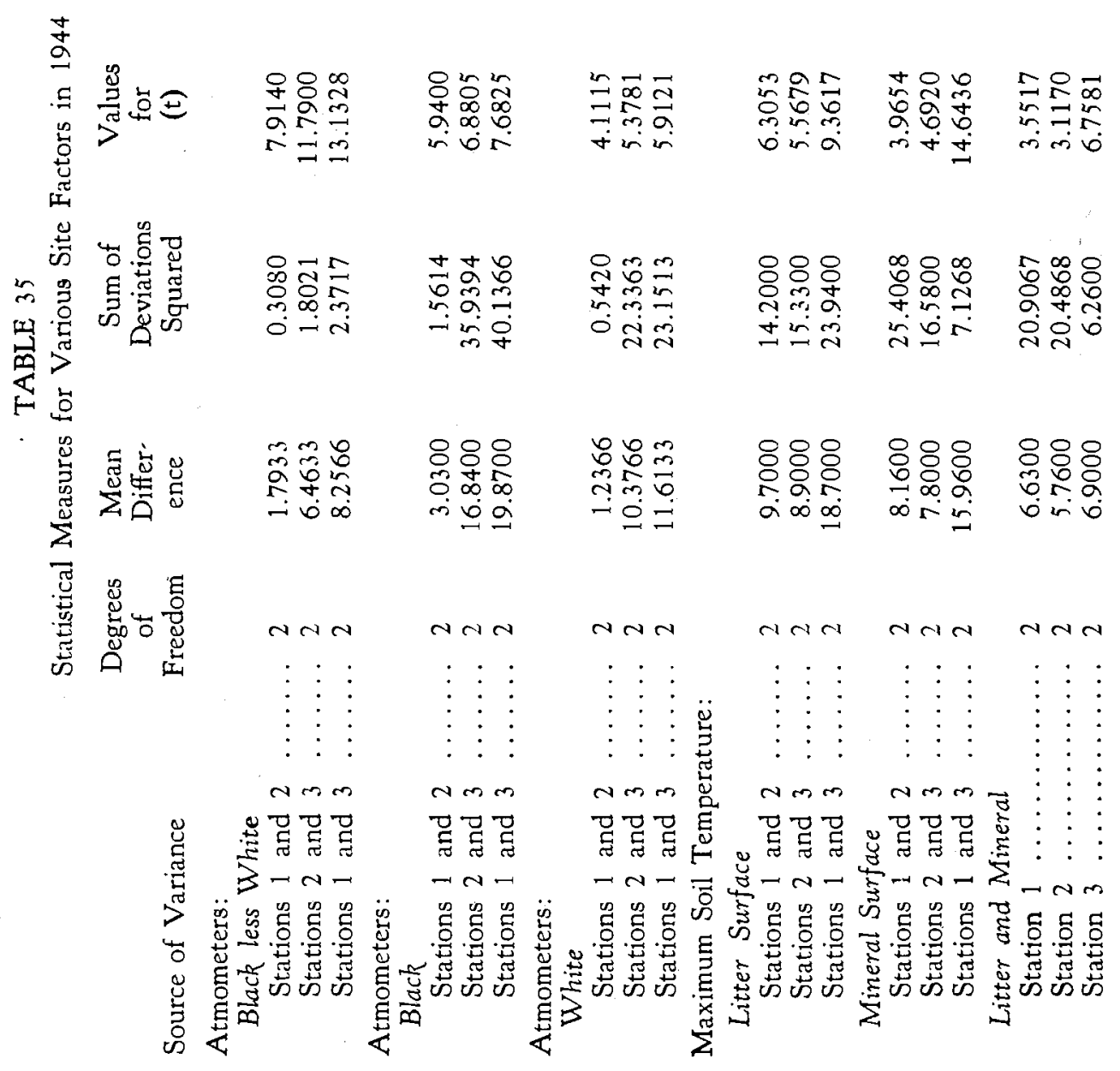




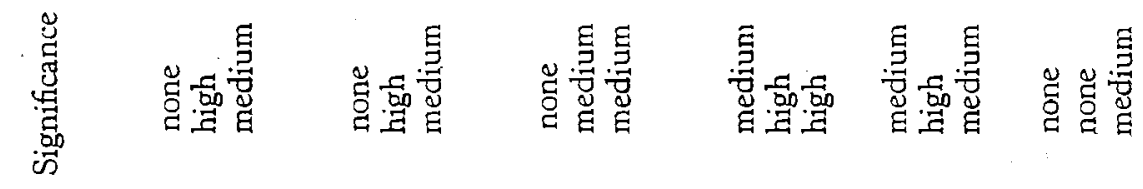

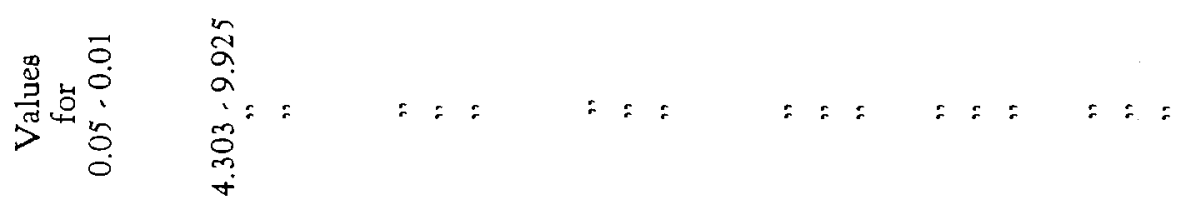

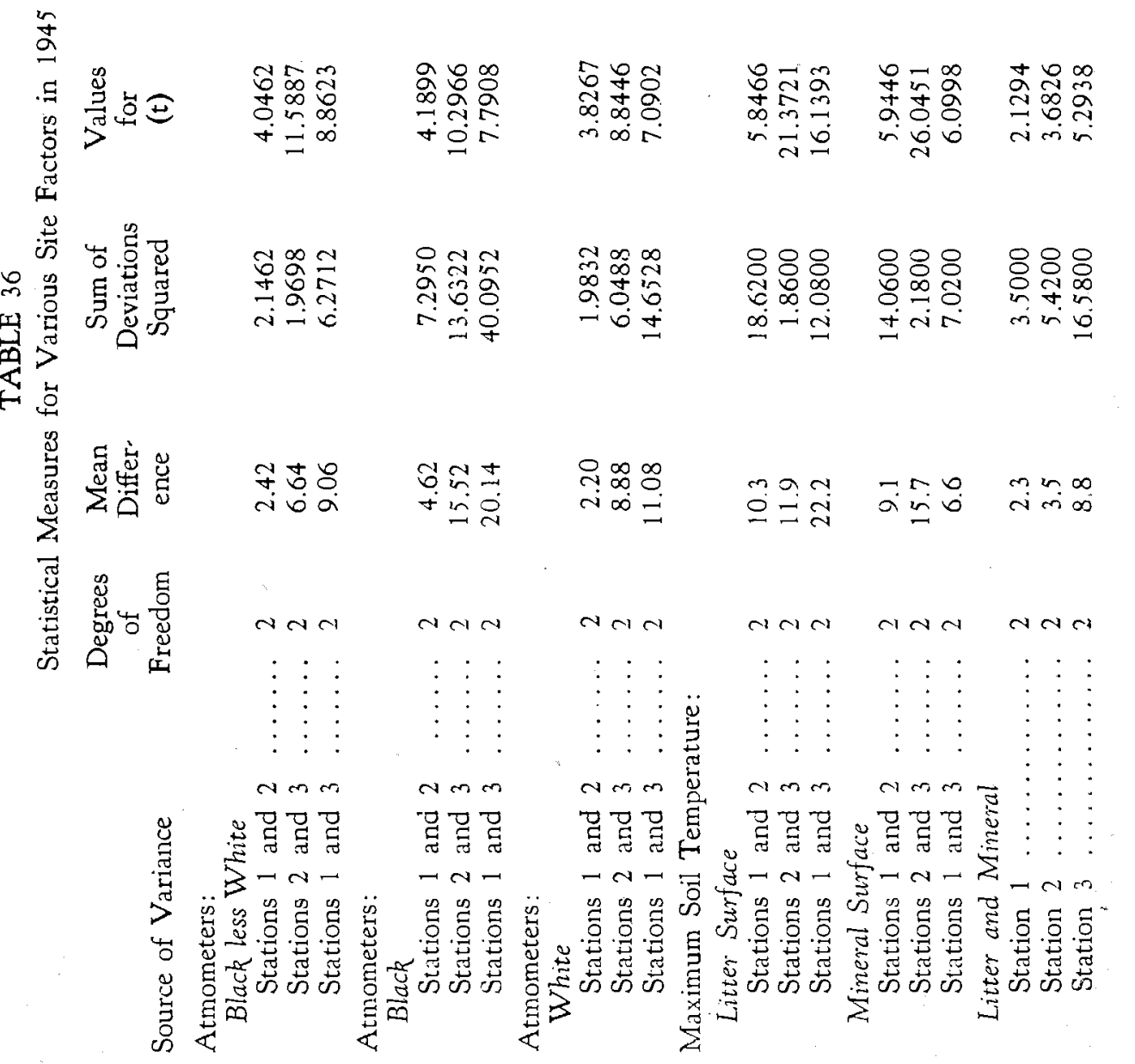




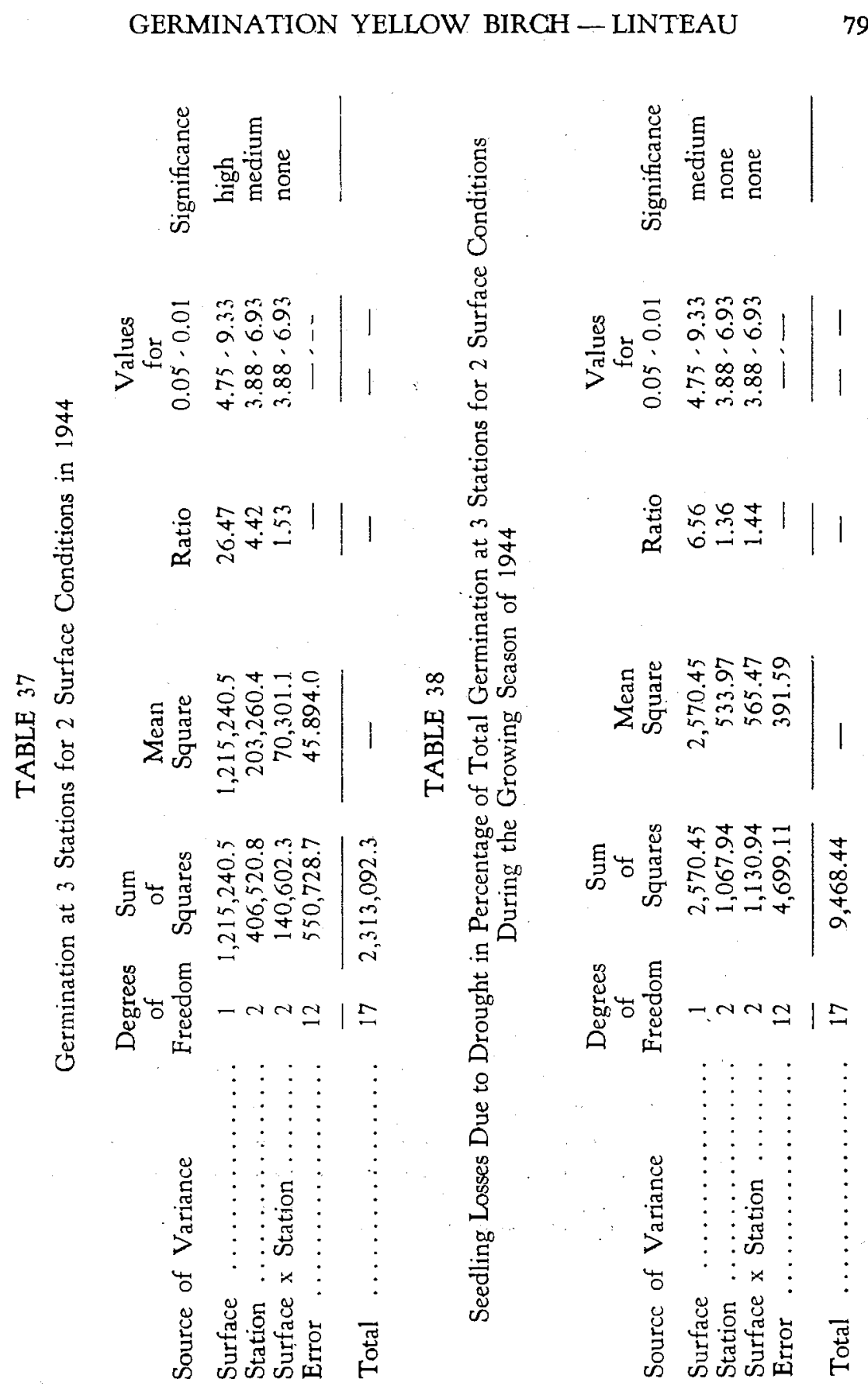




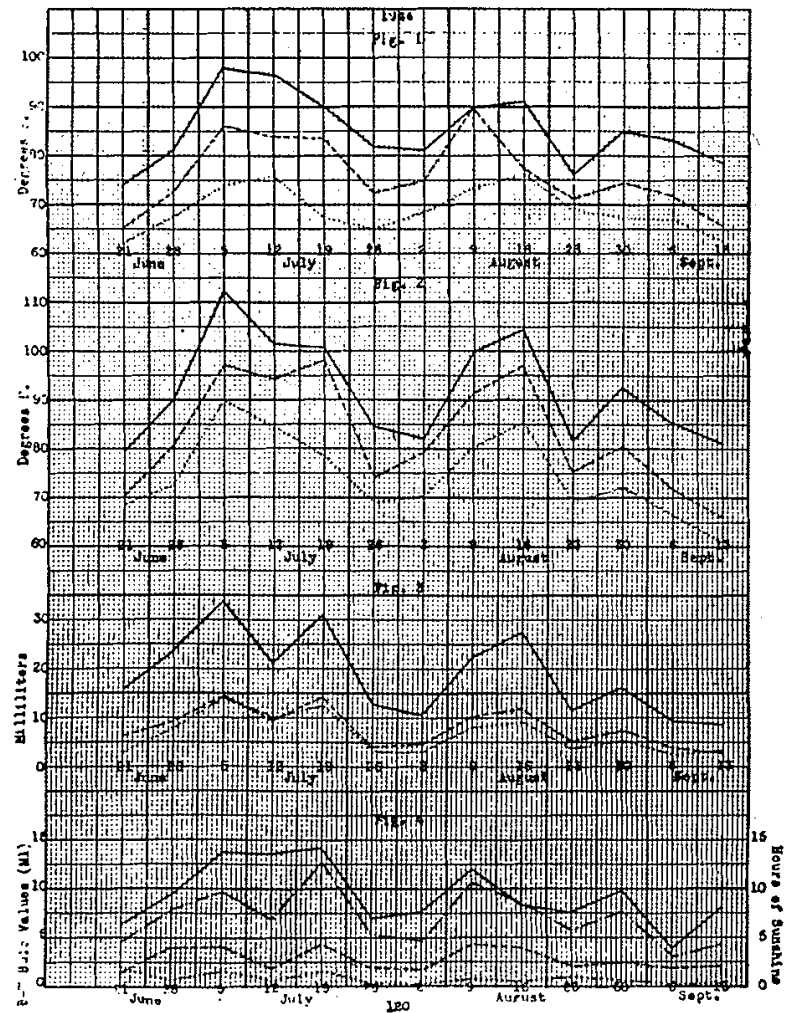

COMPARISON OF SOME IMPORTANT SITE FACTORS TT GROWING SEASON" OF 1944 Lregend

Fig. 1-Mean weekly maximum temperatures $\left({ }^{\circ} \mathrm{F}.\right)$ of mineral soil surfaces. Dates indicate end of weekly periods of observations.

Station I, dotted line: Station II, broken line; Station III, solid line.

Fig. 2-Mean weelly maximum temperatures ( $\left.{ }^{\circ} \mathrm{F}.\right)$ of litter surfaces. Legend for curves is the same as Figure 1.

Fig. 3-Mesn weekly evaporation (ml) at the same stations.

19. Iegend for curves is the same as in Figure 1.

Flg. 4-Mean weekly light conditions (ml) at the same stations. Legend for curves is the same as in Figure 1 . Values indicated are obtained by subtracting the readin of the white bulb from thoge of the black butb. inga the whito bulb from thouk the The fourth curve represente meliograph at the Duchesnay Meteorological Station. 


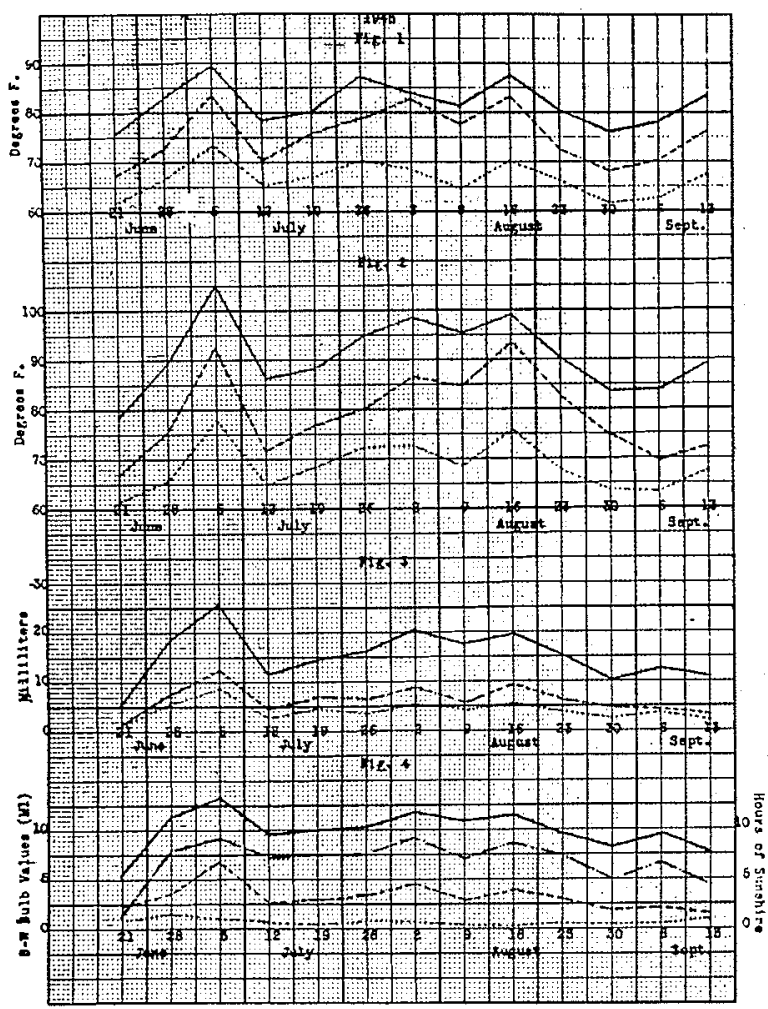

COMPARISON OF SOME IMPORTANT SITE FACTORS AT THE THREE STATIONS DURING THE GROWING SEASON OF 1945

$$
\text { Legend }
$$

Fig. 1-Mean weekly maximum temperatures ( ${ }^{\circ} \mathrm{F}$.) of mineral soil surfaces. Dates indicate end of weekly periods of soil surfaces. Dates indicate end of weekly periods of

Station I, dotted line; Station II, broken line; Station

Fig. 2-Mean weokly maximum temperatures $\left({ }^{\circ} F_{.}\right)$of litter Mean weokly maximum temperatures (

Fig. 3-Mean weekly evaporation (ml) at the same stations. Mean weekly evaporation (ml) as in Figure 1 .

Fig. 4-Megend for cons. Mean weekly light conditions (ml) at the same

Legend for curves is the same as in Figure 1 . alues indicated are obtained by subtracting the readThe fourth curve represents mean weekly hours of sunshine as recorded by the heliograph at the Duchesnay Meteorological Station. 
TABLE 39

Seedling Losses Due to Heat in Percentage of Total Grermination at 3 Stations for 2 Surface Conditions

During the Growing Season of 1944

\begin{tabular}{|c|c|c|c|c|c|c|c|}
\hline $\begin{array}{c}\text { Source } \\
\text { of } \\
\text { Variance }\end{array}$ & $\begin{array}{l}\text { Degrees } \\
\text { of } \\
\text { Freedom }\end{array}$ & $\begin{array}{c}\text { Sum } \\
\text { of } \\
\text { Squares }\end{array}$ & $\begin{array}{c}\text { Mean } \\
\text { Square }\end{array}$ & Ratio & $\begin{array}{r}\begin{array}{r}\text { Valu } \\
\text { fo }\end{array} \\
0.05-\end{array}$ & 0.01 & $\begin{array}{l}\text { Signifi- } \\
\text { cance }\end{array}$ \\
\hline Surface . . & $\ldots 1$ & 189.47 & 189.47 & 4.62 & 4.84 & 9.65 & Medium \\
\hline $\begin{array}{l}\text { Station ... } \\
\text { Surface }\end{array}$ & 2 & 28.76 & 14.38 & 0.35 & 3.98 & 7.20 & None \\
\hline x Station & 2 & 314.99 & 157.49 & 3.89 & $3.98=$ & 7.20 & Medium \\
\hline Error & $\ldots 11$ & 445.44 & 40.49 & - & - & - & \\
\hline otal & $16^{*}$ & & - & - & $\longrightarrow$ & - & \\
\hline
\end{tabular}

* 1 degree of freedom lost by averaging values to fill a cell.

TABLE 40

Seedling Losses Due to Frost in Percentage of Seedlings Present at 3 Stations on Mineral Soil Surface

During the Growing Season of 1945

\begin{tabular}{|c|c|c|c|c|c|c|}
\hline $\begin{array}{c}\text { Source } \\
\text { of } \\
\text { Variance }\end{array}$ & $\begin{array}{l}\text { Degrees } \\
\text { of } \\
\text { Freedom }\end{array}$ & $\begin{array}{c}\text { Sum } \\
\text { of } \\
\text { Squares }\end{array}$ & $\begin{array}{c}\text { Mean } \\
\text { Square }\end{array}$ & Ratio & $\begin{array}{c}\begin{array}{c}\text { Values } \\
\text { for } \\
0.05-0.01\end{array}\end{array}$ & $\begin{array}{l}\text { Signifi- } \\
\text { cance }\end{array}$ \\
\hline Station .. & $\ldots 2$ & $8,156.71$ & $4,078.35$ & 64.23 & $5.14 \cdot 10.92$ & High \\
\hline Error & 6 & 380.93 & 63.49 & - & -- & \\
\hline Total & 8 & $8,537.64$ & - & 一 & - & \\
\hline
\end{tabular}

T.ABLE 41

Survival of Seedlings After 2 Growing Seasons in Percentage of Germination at 3 Stations on Mineral Soil, 1945

\begin{tabular}{|c|c|c|c|c|c|c|}
\hline $\begin{array}{c}\text { Source } \\
\text { of } \\
\text { Variance }\end{array}$ & $\begin{array}{l}\text { Degrees } \\
\text { of } \\
\text { Freedom }\end{array}$ & $\begin{array}{c}\text { Sum } \\
\text { of } \\
\text { Squares }\end{array}$ & $\begin{array}{c}\text { Mean } \\
\text { Square }\end{array}$ & Ratio & 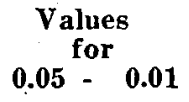 & $\begin{array}{l}\text { Signifi- } \\
\text { cance }\end{array}$ \\
\hline Station . & .. 2 & $7,128.83$ & $3,564.42$ & 70.40 & $5.14-10.92$ & High \\
\hline Error & 6 & 303.76 & 50.63 & - - & -- & \\
\hline Total & 8 & $7,432.59$ & - & - & - & \\
\hline
\end{tabular}


TABLE 42

Average Height of Seedlings After 2 Growing Seasons at 3 Stations on Mineral Soil Surface, 1945

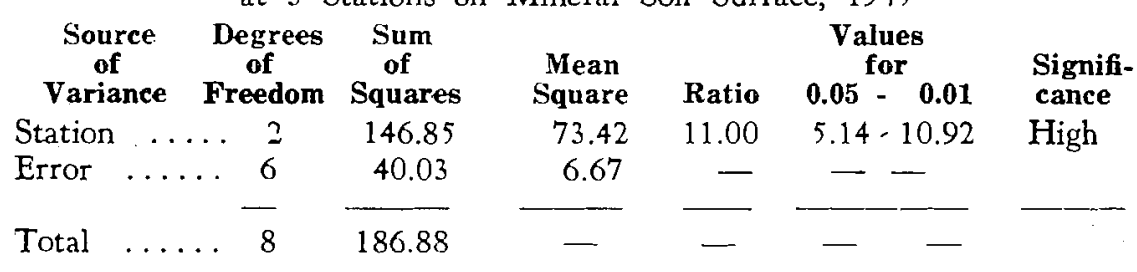

TABLE 43

Stand Table

A Typical 70-year old Yellow Birch-Maple Forest at Duchesnay,Quebec

Number of Trees Per Acre

\begin{tabular}{|c|c|c|c|c|c|c|c|c|}
\hline $\begin{array}{c}\text { Diameter } \\
\text { Breast } \\
\text { Beight }\end{array}$ & $\begin{array}{l}\text { Yellow } \\
\text { Birch }\end{array}$ & $\begin{array}{c}\text { Hard } \\
\text { Maple }\end{array}$ & $\begin{array}{c}\text { Red } \\
\text { Maple }\end{array}$ & $\begin{array}{c}\text { Bulsamm } \\
\text { Fir }\end{array}$ & Beech & $\begin{array}{l}\text { Large } \\
\text { Tooth } \\
\text { Aspen }\end{array}$ & $\begin{array}{c}\text { Red } \\
\text { spruce }\end{array}$ & $\begin{array}{l}\text { Black } \\
\text { Cherry }\end{array}$ \\
\hline 4 & 13.9 & 11.0 & 2.8 & 3.2 & 1.1 & - & - & - \\
\hline 5 & 12.5 & 9.3 & 3.2 & 1.8 & - & - & - & 0.2 \\
\hline 6 & 17.5 & 4.3 & 4.3 & 1.8 & - & $\ldots$ & - & 0.3 \\
\hline 7 & 19.3 & 4.6 & 5.0 & 1.4 & 1.1 & - & - & 0.3 \\
\hline 8 & 15.0 & 4.3 & 3.9 & 1.1 & 0.3 & - & 0.3 & 0.3 \\
\hline 9 & 19.6 & 2.2 & 2.8 & 0.7 & 1.1 & - & - & - \\
\hline 10 & 13.6 & 1.4 & 2.5 & 0.7 & - & - & 0.3 & - \\
\hline 11 & 10.0 & 1.1 & 2.2 & $0 . \hat{3}$ & 1.1 & - & - & - \\
\hline 12 & 12.8 & 0.7 & 1.1 & 1.1 & - & - & - & - \\
\hline 13 & 3.5 & 0.4 & 1.8 & 0.3 & - & 0.3 & - & - \\
\hline 14 & 4.3 & 0.7 & 1.8 & 0.3 & 0.3 & - & - & - \\
\hline 15 & 3.5 & 1.1 & 1.1 & 0.7 & 0.7 & - & - &.- \\
\hline 16 & 1.8 & 0.3 & 0.7 & - & - & - & - & - \\
\hline 17 & 0.7 & 0.7 & 0.7 & 0.3 & - & - & - & - \\
\hline 18 & 1.0 & - & 0.7 & 0.3 & - & - & - & - \\
\hline 19 & 0.0 & - & - & - & - & - & - & — \\
\hline 20 & 0.0 & - & - & - & - & - & - & - \\
\hline 21 & 0.3 & - & - & - & - & - & - & - \\
\hline 22 & 0.0 & - & - & - & - & - & - & $\ldots$ \\
\hline 23 & 0.7 & - & - & - & - & - & $\ldots$ & - \\
\hline \multirow[t]{2}{*}{ Total } & 150.0 & 41.4 & 34.6 & 14.0 & 5.7 & 0.3 & 0.6 & 1.1 \\
\hline & & & No. & Trees & 247.7 & & & \\
\hline ercentage & 60.6 & 16.7 & 13.9 & 5.7 & 2.3 & 0.1 & 0.2 & 0.5 \\
\hline
\end{tabular}


TABLE 44

Analysis of the Lesser Vegetation

Duchesnay, Quebec

(Full Canopy)

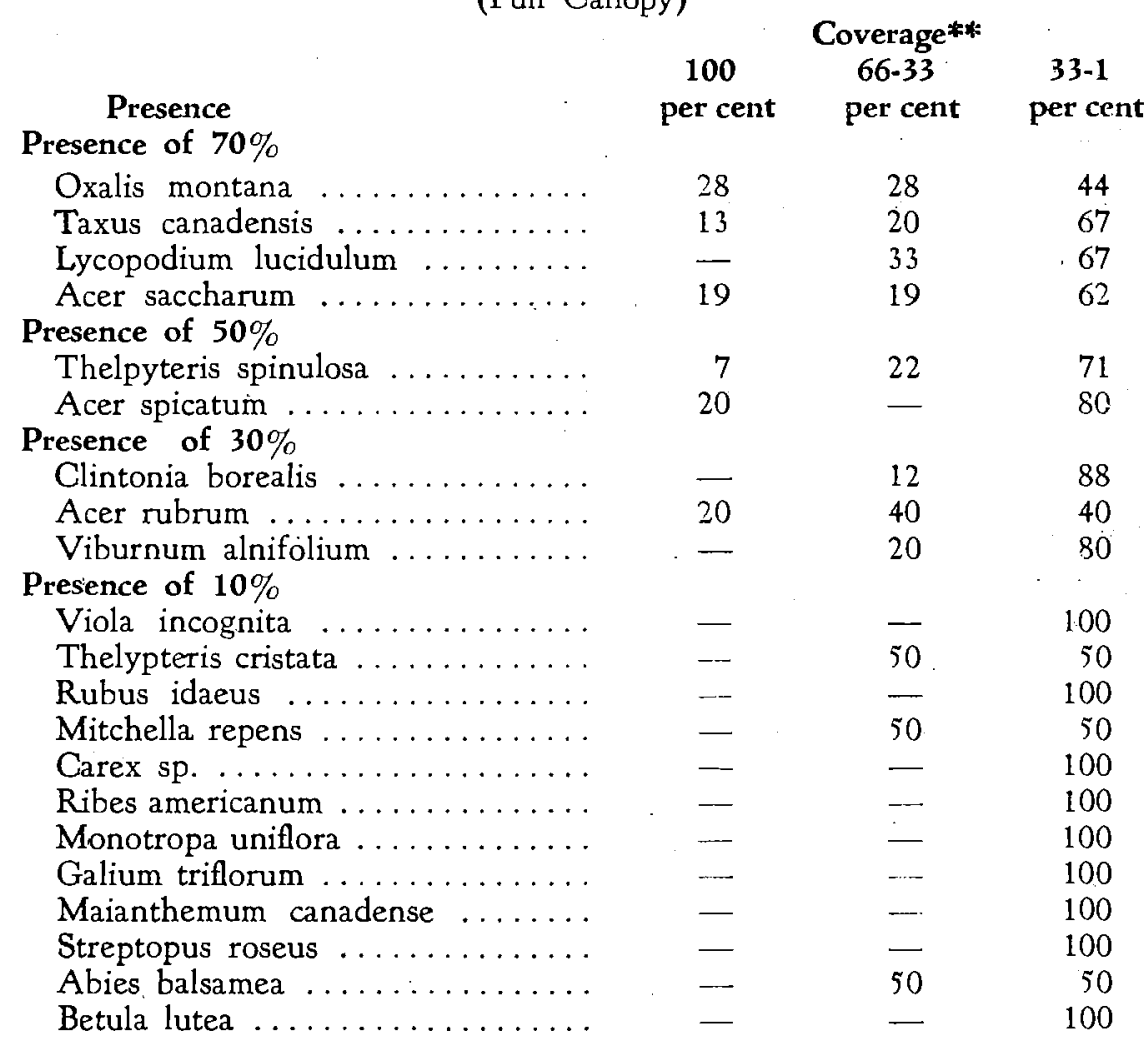

*The term Presence indicates the relative occurrence or frequency of a plant.

**The term Coverage indicates the relative surface area covered by one or more individuals of a certain species in a $1.5 \times 1.5$ foot square, e.g., Oxalis montana has been found in 70 per cent of the sample plots taken. On 28 per cent of these plots the species covered the whole area; on 28 per cent of these plots $1 / 3$ to $2 / 3$ of the square area was covered by the same species, etc. 
TABLE 45

Analysis of the Lesser Vegetation

Duchesnay, Quebec

Station II

(Partial Canopy)

Presence*

Presence of $90 \%$

Oxalis montana

Presence of $50 \%$

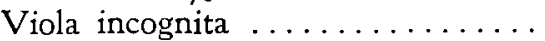

Thelypteris cristata $\ldots \ldots \ldots \ldots \ldots$

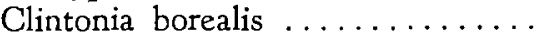

Acer spicatum ..............

Acer rubrum ...............

Presence of $30 \%$

Rubus idaeus ..............

Betula lutea ...............

Thelypteris spinulosa ..........

Maianthemum canadense ........

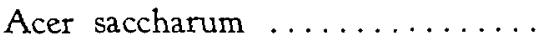

Taxus canadensis $\ldots \ldots \ldots \ldots \ldots$

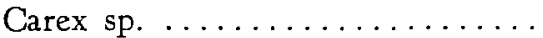

Abies balsamea .............

Presence of $10 \%$

Lycopodium lucidulum .........

Polytrichum strictum .........

Aralia nudicaulis . . . . . . . . .

Mitchella repens ............

Prunus pennsylvanica .........

Viburnum alnifolium .........

Trientalis borealis ............

Cornus canadensis ...........

Aster acuminatus $\ldots \ldots \ldots \ldots$.

100
per cent

\section{Coverage**:} 66-33 per cent

33-1

27

36

per cent

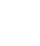

37

20

-

100

30

16

25

8

7

$-\quad 10$
$-\quad 33$

33
28

15

$\overline{16}$

$-$

$$
20
$$

- 20

-

-

- $\quad 25$

$$
25
$$$$
\text { - } \quad \text { - }
$$

50

- $\quad 50$

- $\quad-$

100

*The term Presence indicates the relative occurrence or frequency of a plant.

**The term Coverage indicates the relative surface area covered by one or more individuals of a certain species in a $1.5 \times 1.5$ foot square, e.g., Oxalis montana has been found in 70 per cent of the sample plots taken. On 28 per cent of these plots the species covered the whole area; on 28 per cent of these plots $1 / 3$ to $2 / 3$ of the square area was covered by the same species, etc. 
TABLE 46

Analysis of the Lesser Vegetation

Duchesnay, Quebec

Station III

(Open)

\begin{tabular}{|c|c|c|c|}
\hline & & & \\
\hline & & Coverage*** & \\
\hline Presence* & $\begin{array}{c}100 \\
\text { per cent }\end{array}$ & $\begin{array}{c}66-33 \\
\text { per cent }\end{array}$ & $\begin{array}{c}33-1 \\
\text { per cent }\end{array}$ \\
\hline Presence of $90 \%$ & & & \\
\hline Rubus idaeus. & 40 & 24 & 36 \\
\hline Presence of $70 \%$ & & & \\
\hline Betula lutea .. & - & 28 & 72 \\
\hline Presence of $50 \%$ & & & \\
\hline Sambucus racemosa & 9 & 9 & 82 \\
\hline Polytrichum strictum & - & 45 & 55 \\
\hline Prunus pennsylvanica & - & 45 & 55 \\
\hline Populus tremuloides & - & 27 & 73 \\
\hline Presence of $30 \%$ & & & \\
\hline Carex sp. ......... & - & - & 100 \\
\hline Thelypteris spinulosa & - & 20 & 80 \\
\hline Presence of $10 \%$ & & & \\
\hline Acer saccharum ........ & - & 25 & 75 \\
\hline Maianthemum canadense $\ldots \ldots \ldots$ & $\ldots$ & - & 100 \\
\hline Taxus canadensis ............ & - & _- & 100 \\
\hline Acer rubrum .... & $\ldots$ & $\ldots$ & 100 \\
\hline Tiarella cordifolia & - & _- & 100 \\
\hline Fagus grandifolia $\ldots \ldots \ldots \ldots$ & — & - & 100 \\
\hline Viburnum alnifolium..$\ldots \ldots$ & - & - & 100 \\
\hline
\end{tabular}

*The term Presence indicates the relative occurrence or frequency of a plant.

**The term Coverage indicates the relative surface area covered by one or more individuals of a certain species in a $1.5 \times 1.5$ foot square, e.g., Oxalis montana has been found in 70 per cent of the sample plots taken. On 28 per cent of these plots the species covered the whole area; on 28 per cent of these plots $1 / 3$ to $2 / 3$ of the square area was covered by the same species, etc. 